\title{
Evaluating the Met Office Unified Model land surface temperature in Global Atmosphere/Land 3.1 (GA/L3.1), Global Atmosphere/ Land 6.1 (GA/L6.1) and limited area $2.2 \mathrm{~km}$ configurations
}

\author{
Jennifer K. Brooke ${ }^{1}$, R. Chawn Harlow ${ }^{1}$, Russell L. Scott ${ }^{2}$, Martin J. Best ${ }^{1}$, John M. Edwards ${ }^{1}$, Jean-Claude Thelen ${ }^{1}$, \\ and Mark Weeks ${ }^{1}$ \\ ${ }^{1}$ Met Office, Fitzroy Road, Exeter, EX1 3PB, UK \\ ${ }^{2}$ Southwest Watershed Research Center, USDA-ARS, 2000 E. Allen Road, Tucson, AZ 85719, USA
}

Correspondence: J. K. Brooke (jennifer.brooke@metoffice.gov.uk)

Received: 25 October 2018 - Discussion started: 30 November 2018

Revised: 1 April 2019 - Accepted: 7 April 2019 - Published: 29 April 2019

\begin{abstract}
A limitation of the Met Office operational data assimilation scheme is that surface-sensitive infrared satellite sounding channels cannot be used during daytime periods where numerical weather prediction (NWP) model background land surface temperature (LST) biases are greater than $2 \mathrm{~K}$ in magnitude. The Met Office Unified Model (UM) has a significant cold LST bias in semi-arid regions when compared with satellite observations; a range of UM configurations were assessed with different model resolutions, land surface cover datasets and bare soil parameterisations. UM LST biases were evaluated at global resolution and in a limited area model (LAM) at a $2.2 \mathrm{~km}$ resolution over the SALSTICE (Semi-Arid Land Surface Temperature and IASI Calibration Experiment) experimental domain in south-eastern Arizona. This validation is in conjunction with eddy-covariance flux tower measurements. LST biases in the Global Atmosphere/Land 3.1 (GA/L3.1) configuration were largest in the mid-morning with respect to Moderate Resolution Imaging Spectroradiometer (MODIS) Terra $(-13.6 \pm 2.8 \mathrm{~K}$ at the Kendall Grassland site). The diurnal cycle of LST in Global Atmosphere/Land 6.1 (GA/L6.1) showed a significant improvement relative to GA/L3.1 with the cold LST biases reduced to $-1.4 \pm 2.7 \mathrm{~K}$ and $-3.6 \pm 3.0 \mathrm{~K}$ for Terra and Aqua overpasses, respectively. The higherresolution LAM showed added value over the global configurations.

The spatial distribution of the LST biases relative to MODIS and the modelled bare soil cover fraction were found to be moderately correlated $(0.61 \pm 0.08)$ during the daytime, which suggests that regions of cold LST bias are associated
\end{abstract}

with low bare soil cover fraction. Coefficients of correlation with the shrub surface fractions followed the same trend as the bare soil cover fraction, although with a less significant correlation $(0.36 \pm 0.09)$, and indicated that the sparse vegetation canopies in south-eastern Arizona are not well represented in UM ancillary datasets. The $x$ component of the orographic slope was positively correlated with the LST bias $(0.41 \pm 0.05$ for MODIS Aqua) and identified that regions of cold model LST bias are found on easterly slopes, and regions of warm model LST bias are found on westerly slopes. An overestimate in the modelled turbulent heat and moisture fluxes at the eddy-covariance flux sites was found to be coincident with an underestimate in the ground heat flux.

\section{Introduction}

Infrared radiance data from hyperspectral satellite sounding spectrometers make up the largest proportion of assimilated data at the Met Office and over the last 2 decades have had the greatest forecast impact of any type of observation currently assimilated (English et al., 2000; Cardinali, 2009). The assimilation of a small selection of hyperspectral channels has been shown to improve estimates of temperature and humidity profiles for the initial state of numerical weather prediction (NWP) forecasts (Hilton et al., 2012). However, a significant limitation of the assimilation scheme is that surface-sensitive hyperspectral channels cannot be used during daytime periods due to biases in the NWP 
model background land surface temperature (LST) and emissivity. The model background refers to a short-range model forecast; each data assimilation cycle uses newly received observations to update the model background in order to produce a model analysis (Rabier et al., 2005). At the Met Office, IASI (Infrared Atmospheric Sounding Interferometer) surface-sensitive channels, including window channels and lower-tropospheric (below $400 \mathrm{hPa}$ ) sounding channels, are rejected during assimilation windows for observations over land surfaces and during daytime periods (Pavelin and Candy, 2014).

Land surface temperature is the radiative skin temperature of the land, and knowledge of the LST provides information on the temporal and spatial variations of the surface equilibrium state (Kerr et al., 2000). Recently, research trials have been completed at the Met Office which use night-time LST from the European Space Agency GlobTemperature LSTs project (Ghent et al., 2016) in the land data assimilation system; the study demonstrated improvements in near-surface air temperature forecasts and soil temperatures (Candy et al., 2017). The required LST uncertainty for assimilation within the Met Office operational assimilation scheme is less than $2 \mathrm{~K}$ in magnitude, and Candy et al. (2017) highlights the large errors in daytime LST which must be overcome in order to further advance NWP data assimilation. Currently, as LSTs are not assimilated into the operational Unified Model (UM), they provide an independent source of data for assessing the performance of the land surface model's surface exchange and the boundary layer schemes (Edwards, 2010).

There are large systematic biases in the UM background land surface temperature which vary both spatially and temporally, and they occur most strongly in semi-arid regions such as the south-west US, the Sahel, and south-central Asia. Land surface temperature biases in semi-arid regions are not limited to the UM and have been recognised as a source of model error in other land surface models (Guedj et al., 2011; Trigo et al., 2015; Zheng et al., 2012). Zheng et al. (2012) identified a $10 \mathrm{~K}$ cold bias over the western continental US in the Noah land model, and were able to successfully minimise the bias via a new formulation of the momentum and thermal roughness lengths, whereas Chen and Zhang (2009) found that the coupling strength in this model was too strong over short vegetated surfaces. Trigo et al. (2015) showed that the European Centre for MediumRange Weather Forecasts (ECMWF) land surface scheme, HTESSEL (Hydrology Tiles ECMWF Scheme for Surface Exchanges over Land) underestimated the daily amplitude of surface temperature in semi-arid areas. This has resulted in an overestimate of the night-time LST (warm bias) and an underestimate in daytime temperatures (cold bias). Trigo et al. (2015) found that reducing the magnitude of the skin conductivity, which parameterises the thermal connection between the surface and the soil by controlling the heat transfer to the ground by diffusion, led to a strengthening of the amplitude of the simulated diurnal cycle of surface temperature.
Near-surface air temperatures and LST are controlled by the surface energy balance (e.g. Prince et al., 1998). The warming of the land surface is forced by solar heating, and the dissipation of heat is partitioned between the sensible heat flux $(H)$, the latent heat flux (LE), the ground heat flux $(G)$ and the outgoing longwave radiation. The surface albedo describes the fraction of incident solar radiation reflected by a surface and is an important surface property controlling the available energy. The correct partitioning of the surface net radiation between the latent heat fluxes and sensible heat fluxes is critical (Oke, 1987; Rowntree, 1991; Dickinson, 1991) as this drives the diurnal development of the atmospheric boundary layer (Henderson-Sellers and Brown, 1993). The moisture content of the soil has a strong control over the partitioning of available energy between the heat fluxes (Castelli et al., 1999). In coupled models, land surface models (LSMs) provide the surface boundary conditions for atmospheric models; therefore, it is an important challenge in the development of LSMs to represent these processes that control the exchange of water and energy fluxes at the soilatmosphere interface. The Joint UK Land Environment Simulator (JULES) (Best et al., 2011; Clark et al., 2011) is the land surface model that is coupled to the Met Office Unified Model (UM). Global scientific configurations of the land are identified as "Global Land" (GL), whereas the atmosphere is identified as "Global Atmosphere" (GA).

The Semi-Arid Land Surface Temperature and IASI Calibration Experiment (SALSTICE) was carried out during May 2013 in south-eastern Arizona in order to investigate the biases in the land surface temperatures (LST) forecast by the Met Office Unified Model (UM) in this region. Our study focuses on a small semi-arid region in south-eastern Arizona for a domain of $31.25-32.25^{\circ} \mathrm{N}$ and $69-71.5^{\circ} \mathrm{W}$. In this region collocated airborne observations and eddy-covariance flux tower measurements at sites based in the Walnut Gulch Experimental Watershed and the Santa Rita Experimental Range have been made. The SALSTICE airborne campaign took place from 12 to 21 May 2013 with the timing of the airborne campaign designed to occur at the time of maximum LST biases in the UM. The campaign involved the UK Facility for Airborne Atmospheric Measurements (FAAM) BAe-146 aircraft which carried out five flights with the objective of diagnosing the surface temperature errors within the UM. The outcomes of the airborne measurements will be presented in a future paper.

In this study, we consider the term "model bias" to be a model error which is systematic rather than random, and refer to the bias as being the "model background-minus-observed" (B-O), i.e. where a model, on average, underestimates or overestimates a quantity relative to an observed state. The study evaluates statistics of the model background-minusobserved (B-O) residuals for a range of UM model configurations. This study will characterise the spatial distribution and the magnitude of the UM land surface temperature biases in this region in order to understand the mechanisms which 
give rise to the spatial distributions. We diagnose sources of model error using coincident MODIS retrievals and eddycovariance flux tower measurements. This paper will evaluate changes to the magnitude of the LST bias for the month of May (the month of the maximum LST bias) for a 6-year analysis period from 2013 to 2018, and will attribute observed trends to changes in a range of UM model configurations.

This article is arranged as follows: Sect. 2 provides a description of the eddy-covariance sites and the instrumentation deployed, in addition to the MODIS retrievals utilised. The UM configurations used in this evaluation are summarised. Results are presented in Sect. 3, including an assessment of the diurnal cycle of the LST, an evaluation of the LST biases for the UM configurations for different land classification types, and an examination of correlations between the spatial distribution of LST biases with modelled orography and surface fractional cover. An evaluation of the surface energy balance for the coupled UM configurations is presented. Section 4 then presents the conclusions.

\section{Methodology}

\subsection{Eddy-covariance flux tower measurements}

Eddy-covariance measurements offer model verification of the surface exchange processes and provide an opportunity to examine sources of model error by investigating components of the surface energy balance (SEB) in the Unified Model. The model is evaluated at four eddy-covariance flux tower sites: Lucky Hills and Kendall Grassland, located in the USDA-ARS's (US Department of Agriculture - Agricultural Research Service) Walnut Gulch Experimental Watershed, and the Santa Rita Grassland and Santa Rita Mesquite sites, located in the Santa Rita Experimental Range (Scott et al., 2015) - all four sites are located in south-eastern Arizona. The SEB and LST were investigated during the period from 12 to 21 May 2013, coincident with the SALSTICE campaign. In situ measurements of LST from an infrared radiometer at the flux tower sites were further evaluated for the period from 1 to 31 May 2014-2018. The study will evaluate surface temperatures for a 6-year analysis period.

Lucky Hills Shrubland (AmeriFlux site ID: US-Whs) is a site dominated by Chihuahuan Desert shrubs and is defined as open shrubland according to the International GeosphereBiosphere Programme's (IGBP) land cover classification. The Kendall Grassland (US-Wkg) and the Santa Rita Grassland (US-SRG) sites both have perennial bunch grasses as their dominant vegetation and are classified as a semi-arid warm season desert grassland according to IGBP, whereas the Santa Rita Mesquite (US-SRM) is a woody savannah site (IGBP), predominantly vegetated by small mesquite trees and grasses. These semi-arid ecosystems have bare soil cover in the range of $45 \%$ (Santa Rita Grassland) to $63 \%$ (Lucky Hills Shrubland) (Scott et al., 2015).
The data collected at these sites include screen-level air temperature, humidity, winds, longwave and shortwave broadband hemispherical irradiances, sensible and latent heat fluxes, ground heat fluxes, soil temperature, rainfall and land surface temperature (at Lucky Hills and Kendall Grassland). Details regarding the instrumentation and a full description of the eddy-covariance flux tower sites can be found in Scott et al. (2015). Section 2.2.1-2.2.2 will briefly describe the corrections applied to the observational datasets pertinent to the evaluation presented in this study.

\subsubsection{Corrections applied to the eddy-covariance measurements}

Eddy-covariance techniques use measurements of vertical velocity fluctuations and scalar concentration fluctuations to produce a direct estimate of the vertical flux of sensible heat $\left(H_{\text {meas }}\right)$ and latent heat $\left(\mathrm{LE}_{\text {meas }}\right)$. It is well established in the literature that there is difficulty in closing the SEB with eddycovariance measurements associated with underestimates in measured turbulent heat fluxes (Twine et al., 2000; Wilson et al., 2002; Foken et al., 2008). Wilson et al. (2002) showed that these errors can account for $10 \%$ to $30 \%$ of the net radiation, and Scott et al. (2010) found that the energy balance errors for the $30 \mathrm{~min}$ time averaging window account for $17 \%$ $27 \%$ of the net radiation for the eddy-covariance flux tower sites used in this study. It is not expected to be able achieve an instantaneous energy balance closure at every time step due to the vegetation canopy heat storage. However, the canopy storage in the sparse canopies of south-eastern Arizona is generally neglected, as has been done in the methodology applied here.

The near-surface ground heat flux measurements are at a depth of $5 \mathrm{~cm}$ from the surface soil layer, and subsequently a fraction of the surface soil heat flux is not measured. The correction methodology of Scott et al. (2009) has been applied to the ground heat flux data to account for the missing proportion of the soil heat flux. Additionally, soil heat flux plates buried in the soil can introduce measurement biases due to difference in conductivity between the measurement plates and the surrounding soil (Gentine et al., 2012). Finally, the ground heat fluxes are point measurements and as such do not represent the variability of fluxes across the fetch/sensing area in the same manner as the eddy-covariance measurements.

The use of SEB measurements in order to attribute model biases requires the conservation of energy to be achieved. In our study, we assume the sole error is due to under-sampling of the turbulent fluxes by the eddy-covariance measurements, and that it forces closure of the SEB whilst maintaining the Bowen ratio (BR) (Twine et al., 2000). The BR is the ratio of the sensible heat flux to the latent heat flux. In this method it is assumed that the measured ground heat flux $\left(G_{\text {meas }}\right)$ is well measured, and the corrected turbulent heat fluxes $\left(H_{\text {corr }}\right.$ and $\mathrm{LE}_{\text {corr }}$ ) represent closure of the surface energy balance. 


\subsubsection{Corrections applied to the IRT surface temperature measurements}

An Apogee infrared radiometer (Bugbee et al., 1998), or IRT, such as those installed at Lucky Hills and Kendall Grassland, measures the upwelling longwave radiance across a spectral range of 8-14 $\mu \mathrm{m}$. An estimate of the surface temperature can be made via a conversion of the measured upwelling longwave radiance using the Stefan-Boltzmann law and using an assumed surface emissivity of 1.0 (Fiebrich et al., 2003). The broadband emissivity of bare soil can vary substantially with values in the range of 0.81-0.99 (Ogawa et al., 2003). A correction is made to the measured upwelling longwave radiance in order to account for such uncertainty in the surface emissivity, as described below.

The National Land Cover Database (NLCD) 2006 (Fry et al., 2011) has been used to identify shrubland and grassland regions of the SALSTICE airborne flight tracks (described in a future paper). The NLCD 2006 dataset is a 16 class land cover classification scheme that has been applied consistently across the US at a spatial resolution of $30 \mathrm{~m}$. Emissivity retrievals from the airborne ARIES (Airborne Research Interferometer Evaluation System) instrument (Newman et al., 2005) were performed during the SALSTICE campaign (not shown). An 8-14 $\mu \mathrm{m}$ broadband emissivity was calculated for the surface types (shrubland and grassland) found at Kendall Grassland and Lucky Hills. The $8-14 \mu \mathrm{m}$ broadband emissivity was found to be $0.97 \pm 0.02$. The variability in emissivity obtained from the ARIES measurements was found to have a $\pm 1.1 \mathrm{~K}$ uncertainty on the land surface temperature from the daytime IRT measurements.

A further correction is applied which accounts for the downwelling longwave radiation according to Eq. (1):

$$
\begin{aligned}
& \mathrm{BT}_{\text {surf, } 8-14 \mu \mathrm{m}}= \\
& \quad \frac{1}{\varepsilon}\left(\mathrm{LW}_{\text {surf, } 8-14 \mu \mathrm{m}}^{\uparrow}-(1-\varepsilon) \mathrm{LW}_{\text {surf, } 8-14 \mu \mathrm{m}}^{\downarrow}\right),
\end{aligned}
$$

where $\mathrm{BT}_{\text {surf, } 8-14 \mu \mathrm{m}}$ is the surface blackbody radiance, $\varepsilon$ is the emissivity in the range of $0.97 \pm 0.02, \mathrm{LW}_{\text {surf, } 8-14 \mu \mathrm{m}}^{\uparrow}$ is the upwelling radiance at the surface in the IRT field of view and $L W_{\text {surf, 8-14 } \mu \mathrm{m}}^{\downarrow}$ is the downwelling radiance at the surface that is reflected into the IRT field of view.

The $8-14 \mu \mathrm{m}$ downwelling longwave radiance $\left(\mathrm{LW}_{\text {surf, }}^{\downarrow} 8-14 \mu \mathrm{m}\right)$ is modelled using the Havemann-Taylor Fast Radiative Transfer Code (HT-FRTC) (Havemann, 2006) for each of the ground sites, Lucky Hills and Kendall Grassland, which have an IRT installed. Hourly downwelling longwave radiation is calculated using the HT-FRTC based on the ECMWF ERA-Interim (Dee et al., 2011) atmospheric profiles of temperature, specific humidity and ozone mass mixing ratio which are available every $6 \mathrm{~h}(00: 00$, 06:00, 12:00 and 18:00). For the other times, the ECMWF ERA-Interim atmospheric profiles have been interpolated in time. The downwelling calculation does not account for aerosol loading and uses the $8-14 \mu \mathrm{m}$ spectral emissivity for sandy soil from Arizona from UCSB (University of California, Santa Barbara) Emissivity Library (UCSB Library) (https://icess.eri.ucsb.edu/modis/EMIS/html/em.html, last access: 11 February 2019). The IRT measurements were found to be on average (of the 6 years) $-0.51 \mathrm{~K}$ colder when accounting for the reflected downwelling average for the 6 years; the smallest impact was found for the 2014 measurements $(-0.43 \mathrm{~K})$, and the largest impact was found in $2015(-0.59 \mathrm{~K})$.

Cloud screening of the IRT data was performed using coincident observations of downwelling shortwave radiation, as no direct measurement of cloud cover is made at the two AmeriFlux sites. The theoretical clear-sky downwelling shortwave radiation for each site was calculated and compared with the measured downwelling shortwave radiation; times where there was a suppression in the observed downwelling shortwave radiation compared with the theoretical calculation were attributed to the presence of cloud. It was found that on average (for both sites and for the 6 analysis years) the IRT data were $0.45 \mathrm{~K}$ warmer when applying cloud screening which equates to a $-0.45 \mathrm{~K}$ larger cold model bias. Cloud screening of the IRT data had a smaller impact in May 2013 and 2018 with a $-0.2 \mathrm{~K}$ colder model bias compared with not accounting for cloud, and the largest impact was found for May 2015 and 2016 contributing to a $-0.7 \mathrm{~K}$ colder model bias.

The IRT measurements are only presented for daylight hours from 06:00 to 18:00 local solar time. The IRT measurements outside of this time frame were anomalously warm and were identified as being unreliable. The advantage of these measurements is that they give greater diurnal variation at each site recorded at $30 \mathrm{~min}$ intervals, and they compliment MODIS LST retrievals which only have four overpasses per diurnal cycle.

\subsection{MODIS LST retrievals}

The MOD11_L2 and MYD11_L2 LST products are generated using Moderate Resolution Imaging Spectroradiometer (MODIS) radiances at a $1 \mathrm{~km}$ spatial resolution and are comparable with respect to resolution with the $2.2 \mathrm{~km}$ LAM. Retrievals from both Terra (10:00-11:00/22:00-23:00 LT overpass time, MOD11_L2) and Aqua (01:00-02:00/13:0014:00 LT overpass time, MYD11_L2) of LST for the months of May 2013-2018 are utilised. The LST retrieval from the Aqua platform is likely to be closer to the maximum daily LST than that acquired from the Terra platform (Coops et al., 2007).

The MODIS LST retrieval algorithm is described in the MODIS Land-Surface Temperature Algorithm Theoretical Basis Document (Wan and Dozier, 1996; Wan, 1999). In the literature it is found that the Collection 5 (C5) LST product has an accuracy of within 1-2 K (Coll et al., 2005; Wang et 
al., 2007; Wan et al., 2004). More recent studies have shown that the C5 retrievals underestimate LST by more than $3 \mathrm{~K}$ for particular bare soil/sand sites; the MODIS Collection 6 (C6) retrieval was developed to address these biases (Wan, 2014). For this reason we use both C5 and C6 products in our land surface temperature evaluation.

In order to produce an LST retrieval for each eddycovariance flux site, boundaries of constant latitude and longitude were chosen such that the boundaries have tangent points $1 \mathrm{~km}$ away from each ground site. Thus, $2 \mathrm{~km}$ by $2 \mathrm{~km}$ boxes are formed about each site. MODIS pixels whose centres fall within these boxes are selected and averaged to give site-specific LSTs. Therefore, the number of MODIS pixels contributing to one of these site specific values can range from one to five dependent on where the site is within the swath of the instrument. Cloud screening of the MODIS data has been applied; data which were flagged by the MODIS quality algorithm as contaminated by cloud were removed from the analysis.

Li et al. (2013) found that the difference in the LST measured by nadir and off-nadir satellite observations can be as large as $5 \mathrm{~K}$ for bare soils, and $\mathrm{Hu}$ et al. (2014) found that LST measurements with smaller view angles tend to be warmer. Our results support this finding; we find a larger model cold LST biases when considering smaller view angles. Our analysis finds that the average LST bias with respect to Terra (Aqua) was $0.2 \mathrm{~K}(0.3 \mathrm{~K})$ warmer at $40^{\circ}$ relative to $30^{\circ}, 0.6 \mathrm{~K}(0.8 \mathrm{~K})$ at $45^{\circ}$ relative to $30^{\circ}$ and $1.2 \mathrm{~K}$ $(0.88 \mathrm{~K})$ at $50^{\circ}$ relative to $30^{\circ}$. The angular dependence described arises due to different viewing and illumination geometry of the surface; studies have shown that factors including slope orientation relative to sun and properties of the soil and vegetation, such as the heterogeneity and the structure of the vegetation canopy, all contribute to the directional anisotropy (Duffour et al., 2016; Ermida et al., 2014; Rasmussen et al., 2010). Hence, overpasses were only included in the analysis if the incidence angle over the mid-point of the study area was less than $30^{\circ}$.

\subsection{Unified Model configurations}

The relevant configurations of the UM assessed in this paper are summarised in Table 1, which describes model changes between configurations including dynamics, resolution, data assimilation (DA) bias correction, initialisation, land cover and bare soil parameterisations. The operational models at the Met Office are continually monitored and developed in order to minimise systematic model biases and improve forecasts. The changes in all model configurations evaluated in this study are part of the operational model development cycle. Understanding how the model configuration changes impact on surface temperatures in the development cycle, for the purpose of assessing where any advances in the assimilation of greater volumes of hyperspectral satellite sounding data are needed, is an important evaluation. The UM con- figurations referred to in this study are a coupled configuration consisting of specific configurations the UM atmospheric model (GAx.y) and the JULES land surface model (GLx.y).

The global configuration, GA/L3.1, was run at a $25 \mathrm{~km}$ resolution with 70 vertical levels and used the New Dynamics dynamical core to solve the atmosphere's equations of motion (Davies et al., 2005; Walters et al., 2011). The operational GA/L6.1 configuration, introduced in 2015, used the ENDGame dynamical core to solve the atmosphere's equations of motion and used an increased horizontal resolution of $17 \mathrm{~km}$, hereafter referred to as GA/L6.1_17km (Walters et al., 2017). The horizontal resolution of GA/L6.1 was further increased to $10 \mathrm{~km}$ (hereafter referred to as GA/L6.1_10km) which applies to the analysis of May 2018. The vertical resolution remained unchanged for all configurations. The GA/L3.1 configuration outputs 3-hourly diagnostics, and all GA/L6.1 configurations output diagnostics on an hourly basis. The analysis presented in this paper does not use of the first $7 \mathrm{~h}$ of each forecast for all model configurations, as the first 3-6h of a forecast are generally regarded as unreliable due to the model spin-up time (Kasahara et al., 1992).

Bias correcting actively assimilated sounding radiance observations is necessary in order to generate an unbiased forecast analysis (Zhu et al., 2014). The global model used a static bias correction scheme (Harris and Kelly, 2001) in 2013-2015, whereas variational bias correction (VarBC) was introduced from 2016 onwards (Cameron and Bell, 2018). Global model configurations with the _static and _VarBC suffixes indicate the bias correction scheme used. The two schemes treat radiance observations differently, for example, in the static scheme bias corrections are pre-computed for all available sensors and the bias correction is typically updated at 6-12 month intervals. The bias corrections are based on an observation corrected to the model background (background field from previous model run). VarBC, in contrast, is an adaptive bias correction scheme, and the bias for each radiance channel is computed using a linear predictor model. The observations are corrected to the model analysis (rather than the background) given from the 4D-Var assimilation system. ASCAT (Advanced SCATterometer) volumetric surface soil moisture data are assimilated into all global configurations (Dharssi et al., 2011).

The nesting of high-resolution LAMs provide useful information at scales that cannot be provided by lowerresolution global-scale models (Davies, 2014), for example from surface properties, such as orography and vegetation cover, and by better resolving moist physical processes (e.g. clouds, precipitation and visibility). Two operational nested LAMs were run for the contiguous US as part of the National Oceanographic and Atmospheric Administration's Hazardous Weather Testbed at 4.4 and $2.2 \mathrm{~km}$ resolutions (hereafter referred to as US4.4 and US2.2, respectively) (Hanley et al., 2016). The US4.4 was based on the European $4 \mathrm{~km}$ model (EURO4), and the US2.2 was based 
Table 1. Summary of UM configurations from 2013 to 2018. The ratio of the thermal to the momentum roughness lengths is abbreviated to $z_{\mathrm{OH}} / z_{\mathrm{OM}}, z_{\mathrm{OM}}$ is the roughness length of momentum and $\varepsilon$ is the bare soil emissivity.

\begin{tabular}{|c|c|c|c|}
\hline & & Global & US2.2 \\
\hline \multirow{7}{*}{2013} & $x$ & GA/L3.1 & US2.2_ConfigA \\
\hline & (i) Dynamics & New Dynamics (Walters et al., 2011) & New Dynamics (Walters et al., 2011) \\
\hline & (ii) Resolution & $25 \mathrm{~km}$ horizontal resolution & $2.2 \mathrm{~km}$ horizontal resolution \\
\hline & (iii) DA bias correction & Static bias correction & No data assimilation \\
\hline & (iv) Initialisation & - & US4.4, $T+3$ \\
\hline & (v) Land cover & IGBP land cover & IGBP land cover \\
\hline & (vi) Bare soil parameters & $\varepsilon=0.97, z_{\mathrm{OM}}=0.0032 \mathrm{~m}, z_{\mathrm{OH}} / z_{\mathrm{OM}}=0.10$ & $\varepsilon=0.97, z_{\mathrm{OM}}=0.001 \mathrm{~m}, z_{\mathrm{OH}} / z_{\mathrm{OM}}=0.02$ \\
\hline \multirow{7}{*}{2014} & $x$ & GA/L3.1 & US2.2_ConfigB \\
\hline & (i) Dynamics & New Dynamics (Walters et al., 2011) & New Dynamics (Walters et al., 2011) \\
\hline & (ii) Resolution & $25 \mathrm{~km}$ horizontal resolution & $2.2 \mathrm{~km}$ horizontal resolution \\
\hline & (iii) DA bias correction & Static bias correction & No data assimilation \\
\hline & (iv) Initialisation & - & US4.4, $T+3$ \\
\hline & (v) Land cover & IGBP land cover & IGBP land cover \\
\hline & (vi) Bare soil parameters & $\varepsilon=0.97, z_{\mathrm{OM}}=0.0032 \mathrm{~m}, z_{\mathrm{OH}} / z_{\mathrm{OM}}=0.10$ & $\varepsilon=0.90, z_{\mathrm{OM}}=0.001 \mathrm{~m}, z_{\mathrm{OH}} / z_{\mathrm{OM}}=0.02$ \\
\hline \multirow{7}{*}{2015} & $x$ & GA/L6.1_17km_static & US2.2_ConfigC \\
\hline & (i) Dynamics & ENDGame (Walters et al., 2017) & ENDGame (Walters et al., 2017) \\
\hline & (ii) Resolution & $17 \mathrm{~km}$ horizontal resolution & $2.2 \mathrm{~km}$ horizontal resolution \\
\hline & (iii) DA bias correction & Static bias correction & No data assimilation \\
\hline & (iv) Initialisation & IGBP land cover & GA/L6.1_17km_static, $T+0$ \\
\hline & (v) Land cover & - & IGBP land cover \\
\hline & (vi) Bare soil parameters & $\varepsilon=0.90, z_{\mathrm{OM}}=0.001 \mathrm{~m}, z_{\mathrm{OH}} / z_{\mathrm{OM}}=0.02$ & $\varepsilon=0.90, z_{\mathrm{OM}}=0.001 \mathrm{~m}, z_{\mathrm{OH}} / z_{\mathrm{OM}}=0.02$ \\
\hline \multirow{7}{*}{2016} & $x$ & GA/L6.1_17km_VarBC & US2.2_ConfigD \\
\hline & (i) Dynamics & ENDGame (Walters et al., 2017) & ENDGame (Walters et al., 2017) \\
\hline & (ii) Resolution & $17 \mathrm{~km}$ horizontal resolution & $2.2 \mathrm{~km}$ horizontal resolution \\
\hline & (iii) DA bias correction & Variational bias correction (VarBC) & No data assimilation \\
\hline & (iv) Initialisation & - & GA/L6.1_17km_VarBC, $T+0$ \\
\hline & (v) Land cover & IGBP land cover & IGBP land cover \\
\hline & (vi) Bare soil parameters & $\varepsilon=0.90, z_{\mathrm{OM}}=0.001 \mathrm{~m}, z_{\mathrm{OH}} / z_{\mathrm{OM}}=0.02$ & $\varepsilon=0.90, z_{\mathrm{OM}}=0.001 \mathrm{~m}, z_{\mathrm{OH}} / z_{\mathrm{OM}}=0.02$ \\
\hline \multirow{7}{*}{2017} & $x$ & GA/L6.1_17km_VarBC & US2.2_ConfigD \\
\hline & (i) Dynamics & ENDGame (Walters et al., 2017) & ENDGame (Walters et al., 2017) \\
\hline & (ii) Resolution & $17 \mathrm{~km}$ horizontal resolution & $2.2 \mathrm{~km}$ horizontal resolution \\
\hline & (iii) DA bias correction & Variational bias correction (VarBC) & No data assimilation \\
\hline & (iv) Initialisation & - & GA/L6.1_17km_VarBC, $T+0$ \\
\hline & (v) Land cover & IGBP land cover & IGBP land cover \\
\hline & (vi) Bare soil parameters & $\varepsilon=0.90, z_{\mathrm{OM}}=0.001 \mathrm{~m}, z_{\mathrm{OH}} / z_{\mathrm{OM}}=0.02$ & $\varepsilon=0.90, z_{\mathrm{OM}}=0.001 \mathrm{~m}, z_{\mathrm{OH}} / z_{\mathrm{OM}}=0.02$ \\
\hline \multirow{7}{*}{2018} & $x$ & GA/L6.1_10km_VarBC & US2.2_ConfigE \\
\hline & (i) Dynamics & ENDGame (Walters et al., 2017) & ENDGame (Walters et al., 2017) \\
\hline & (ii) Resolution & $10 \mathrm{~km}$ horizontal resolution & $2.2 \mathrm{~km}$ horizontal resolution \\
\hline & (iii) DA bias correction & Variational bias correction (VarBC) & No data assimilation \\
\hline & (iv) Initialisation & - & GA/L6.1_10km_VarBC, $T+0$ \\
\hline & (v) Land cover & IGBP land cover & ESA Land Cover CCI \\
\hline & (vi) Bare soil parameters & $\varepsilon=0.90, z_{\mathrm{OM}}=0.001 \mathrm{~m}, z_{\mathrm{OH}} / z_{\mathrm{OM}}=0.02$ & $\varepsilon=0.90, z_{\mathrm{OM}}=0.001 \mathrm{~m}, z_{\mathrm{OH}} / z_{\mathrm{OM}}=0.02$ \\
\hline
\end{tabular}


on the UKV (variable resolution UK model for kilometrescale forecasting) operational model. The US4.4 was initialised from the GA/L3.1 T+0 analyses and driven by hourly GA/L3.1 lateral boundary conditions. US2.2_ConfigA-B were nested within the US4.4, initialised from the US4.4 $T+3$ forecast conditions and driven by hourly US4.4 lateral boundary conditions. There was no additional data assimilation in the LAMs. No further configurations of the US4.4 were run beyond 2014, and for this reason the US4.4 is not fully evaluated in this study. The US2.2 (ConfigC-E, 20152018) was initialised directly from the GA/L6.1 T+0 analyses and driven by hourly GA/L6.1 lateral boundary conditions. Specifically, US2.2_ConfigC was initialised from GA/L6.1_17km_static T+0; US2.2_ConfigD was initialised from GA/L6.1_17km_VarBC T+0; US2.2_ConfigE was initialised from GA/L6.1_10km_VarBC $T+0$.

All global configurations and US2.2_ConfigA-D use the International Geosphere-Biosphere Programme's (IGBP) land cover classification dataset for the surface fractional cover mapped to JULES' five plant functional types (PFTs). US2.2_ConfigE uses the surface fractional cover based on the European Space Agency's Land Cover Climate Change Initiative (ESA LC_CCI) global vegetation distribution (Poulter et al., 2015; Harper et al., 2016), mapped to JULES' five PFTs.

A tiled approach is used to represent sub-grid scale heterogeneity (Essery et al., 2003); the surface of each land point is subdivided into five types of vegetation, known as PFTs (broadleaf trees, needleleaf trees, temperate C3 grass, tropical C4 grass and shrubs) and four non-vegetated surface types (urban areas, inland water, bare soil and land ice). Surface exchange on these nine surface tiles can be calculated in two ways: on each tile separately or by aggregating the surface properties on a single tile representing a grid-box mean. The global configurations amalgamate the properties of each surface tile, weighted by their grid-box fraction, into a single representative parameter value. As such there was no representation of sub-grid heterogeneity (Walters et al., 2011). In contrast to this, the fluxes between the land surface and the atmosphere were calculated on each of the nine surface tiles independently for the US2.2.

A series of land surface parameters were varied between UM configurations as part of the operational implementation in order to improve the representation of near-surface temperature gradients and surface fluxes. These land surface parameters are summarised in Table 1. In GA/L3.1 and US2.2_ConfigA the surface emissivity was set to 0.97 over all land surface tiles; however, this was seen to cool the surface too strongly in desert regions (Walters et al., 2017). In all GA/L6.1 configurations and US2.2_ConfigB-E individual surface tiles were assigned different emissivity parameter values: bare soil uses an emissivity of 0.90 , and C3 grasses, C4 grasses and shrubs use an emissivity of 0.98 . To summarise the emissivity changes, an emissivity map of the study region for each configuration is presented in Fig. S1 in the Supplement. The emissivity changes relative to GA/L3.1 (Fig. S1a) and US2.2_ConfigA (Fig. S1d) result in regional decreases for GA/L6.1 (Fig. S1b, c) and US2.2ConfigA-D (Fig. S1e) associated with regions of larger bare soil fractions. US2.2ConfigE (Fig. S1f), in contrast, shows an increase in emissivity for the study domain related to a reduction in the bare soil cover fraction. Section 3.3 provides a more thorough discussion of the surface heterogeneity and land cover in each model configuration.

Surface exchange is treated using the Monin and Obukhov (1954) mean similarity theory. The roughness length of heat $\left(z_{\mathrm{OH}}\right)$ is required to estimate the sensible heat flux and can be considered relative to that of momentum (zOM) via the simple ratio of $z_{\mathrm{OM}} / z_{\mathrm{OH}}$. GA/L3.1 uses a bare soil roughness length $\left(z_{\mathrm{OM}}\right)$ of $0.0032 \mathrm{~m}$, and the ratio of roughness lengths for heat and momentum, $z_{\mathrm{OH}} / z_{\mathrm{OM}}$, was set to 0.1 for all land surface types. In all GA/L6.1 configurations (17km_static, 17km_VarBC and 10km_VarBC) and all configurations of the US2.2, the bare soil roughness length was reduced to $0.001 \mathrm{~m}$ and the ratio $z_{\mathrm{OH}} / z_{\mathrm{OM}}$ was treated independently for each surface type; the bare soil $z_{\mathrm{OH}} / z_{\mathrm{OM}}$ was decreased to 0.02 (Walters et al., 2014, 2017). The $z_{\mathrm{OH}} / z_{\mathrm{OM}}$ ratio was revised between GA/L3.1 and GA/L6.1 in order to improve both land surface temperature and near-surface air temperatures in desert regions. The revised $z_{\mathrm{OH}} / z_{\mathrm{OM}}$ ratio was adopted in US2.2 (and other LAMs) from 2013, whereas GA/L6.1 was adopted for operational use in July 2014.

Model cloud-clearing was performed for all model configurations based on a threshold of total cloud fraction greater than 0.1 for each model grid box. In cases where the combination of model and MODIS cloud clearing resulted in a fraction of the domain containing less than $10 \%$ of the data, the comparison was excluded from the analysis as this was taken to indicate cloud in the region that could affect the measurements.

The surface temperature biases (observed-minus-model background, O-B) for the southern part of the North American continent are presented in Fig. 1 for IASI 1DVAR retrievals compared with two UM global configurations, GA/L3.1 (May 2013) and GA/L6.1_17km_static (May 2015). Please note that Fig. 1 presents the surface temperature bias as $\mathrm{O}-\mathrm{B}$, whereas the paper is presented for the model-background-minus-observed (B-O) hereafter. The IASI 1D-Var retrievals have a spatial resolution of $11 \mathrm{~km}$ and have been re-gridded to a half degree global resolution. In terms of model background-minus-observed surface temperature biases, it can be seen that GA/L3.1-IASI 1D-VAR gives rise to an east-west spatial divide in the magnitude of LST biases with LST cold biases in excess of $-10 \mathrm{~K}$ in the southwest US, western Mexico and extending east into the Great Plains. Moderate cold LST biases extend into the northern US with biases in the range of -4 to $-6 \mathrm{~K}$. The North American mean bias is reduced in GA/L6.1_17km_static-IASI 1D- 
VAR compared with GA/L3.1-IASI 1D-VAR, although regional biases such as the south-west US are still prominent.

\section{Results and discussion}

\subsection{Representation of the diurnal cycles of LST}

The model diurnal cycles in surface temperature for Kendall Grassland are compared in Fig. 2 against observations. The GA/L3.1 diurnal cycle (Fig. 2a) highlights a cold model prediction when compared with MODIS retrievals; daytime biases are in the ranges of $-13.6 \pm 2.8 \mathrm{~K}$ and $-8.8 \pm 2.5 \mathrm{~K}$ for Terra and Aqua overpasses, respectively. Biases in modelled LST are larger in the mid-morning associated with the Terra overpass which indicates that the model struggles to capture the magnitude of the warming from the morning transition to the late morning period. Observations from Aqua are made around the time of the maximum LST when surface temperatures are changing less rapidly than during Terra observations. The biases seen with MODIS are consistent when compared with measurements from the IRT (bias of $-7.5 \pm 3.2 \mathrm{~K})$.

The US2.2_ConfigA diurnal cycle (Fig. 2b) shows that the phase of the surface temperature is improved relative to GA/L3.1. The US2.2_ConfigA configuration improves the timing of the initial warming during the morning transition, and the bias relative to Terra $(7.6 \pm 2.4 \mathrm{~K})$ is improved as a consequence. The underestimate at the time of the diurnal maximum remains in the US2.2_ConfigA and the magnitude of the cold bias is approximately equal to GA/L3.1.

The diurnal cycle of surface temperature in GA/L6.1_17km_static (Fig. 2c) shows a significant improvement relative to GA/L3.1. The cold LST biases are reduced to $-1.4 \pm 2.7 \mathrm{~K}$ and $-3.6 \pm 3.0 \mathrm{~K}$ for Terra and Aqua overpasses, respectively. Additionally, there is an improved overlap of the $1 \sigma$ confidence intervals for the daytime LST measured by the ground-based IRT and for GA/L6.1_17km_static. The US2.2_ConfigC (Fig. 2d) shows a further small improvement of the LST bias relative to the GA/L6.1_17km_static configuration, although not to the same extent as was seen between GA/L3.1 and the US2.2_ConfigA. Biases in US2.2_ConfigA are reduced to $-1.3 \pm 2.1 \mathrm{~K}$ (with respect to Terra) and $-2.5 \pm 1.6 \mathrm{~K}$ (with respect to Aqua).

The LSTs measured at the ground sites are from Apogee IRT radiometers installed at $4 \mathrm{~m}$ and have a field of view which covers approximately $9 \mathrm{~m}^{2}$. The model grid squares that contain these sites are large and in the case of the GA/L3.1 and GA/L6.1_17km_static cover large elevation ranges within one grid square. As the model configurations have grid squares that are many orders of magnitude larger than this, the IRT-measured LSTs greatly under-sample the variability within the model grid square; however, despite this, Fig. 2c and d demonstrate good agreement in the representation of the daytime diurnal cycle.

\subsection{Evaluation of UM surface temperatures at eddy-covariance sites}

This section extends the analysis to the four eddy-covariance sites, evaluates surface temperatures for different land classification types and attributes observed trends to changes in a range of UM model configurations. Figure 3 presents the daytime LST biases for the UM configurations relative to MODIS C6 Terra and Aqua retrievals for the 6 years in the analysis (2013-2018, row 1-6).

The US2.2_ConfigA-D have a smaller cold surface temperature biases compared with the corresponding global configuration from 2013 to 2017. The higher-resolution US2.2 generally has a smaller daytime bias than the US4.4 (approximately $1 \mathrm{~K}$ smaller, data not shown). The US2.2 configurations have higher-resolution ancillary datasets which better resolve surface properties (such as orography and surface fractional cover), and subsequently improve the model representation of the surface heterogeneity, than the GA/L3.1 and GA/L6.1 configurations. In addition, there is a reduction in the bare soil roughness length parameterisation (Table 1) in the US2.2_ConfigA $\left(z_{\mathrm{OM}}=0.0010 \mathrm{~m}\right.$ and $\left.z_{\mathrm{OH}} / z_{\mathrm{OM}}=0.02\right)$ compared with GA/L3.1 $\left(z_{\mathrm{OM}}=0.0032 \mathrm{~m}\right.$ and $z_{\mathrm{OH}} / z_{\mathrm{OM}}=$ 0.10 ) which is required to estimate the sensible heat flux. A smaller roughness length for heat results in a smaller sensible heat flux, and hence a smaller heat flux from the land surface to the atmosphere.

Improvements in LST biases in the US2. 2 configurations, compared with GA/L3.1, are greater at the shrubland sites, Lucky Hills and Santa Rita Mesquite, compared with the grassland sites, Kendall Grassland and Santa Rita Grassland. At Lucky Hills, for example, biases with respect to Aqua are reduced from $-8.2 \pm 2.5 \mathrm{~K}(\mathrm{GA} / \mathrm{L} 3.1,2013)$ to $-3.8 \pm$ $1.9 \mathrm{~K}$ (US2.2_ConfigA). In contrast, at Santa Rita Grassland, the biases are reduced to a lesser extent from $-10.7 \pm$ $3.4 \mathrm{~K}$ (GA/L3.1, 2013) to $-7.3 \pm 1.7 \mathrm{~K}$ (US2.2_ConfigA), and at Kendall Grassland the bias with respect to Aqua is unchanged between GA/L3.1 and US2.2_ConfigA. The IRT measurements support this trend: at Lucky Hills the bias is reduced from $-9.0 \pm 3.7 \mathrm{~K}(\mathrm{GA} / \mathrm{L} 3.1)$ to $-3.3 \pm$ $2.3 \mathrm{~K}$ (US2.2_ConfigA), whereas the IRT measurements at Kendall Grassland only show a $2.2 \mathrm{~K}$ improvement in the US2.2_ConfigA compared with GA/L3.1.

The higher-resolution ancillaries in the US2.2 configurations improve the surface fractions for the two shrubland sites; the US2.2 increases the bare soil fractional cover which acts to increase the sparsity of the vegetation cover, and improves the model representation of the surface heterogeneity. At the Lucky Hills shrubland site, for example, the bare soil fraction is increased from $0.26(\mathrm{GA} / \mathrm{L} 3.1)$ to 0.48 (US2.2_ConfigA-D), and at Santa Rita Mesquite a similar increase from 0.22 (GA/L3.1) to 0.37 (US2.2_ConfigA-D) 


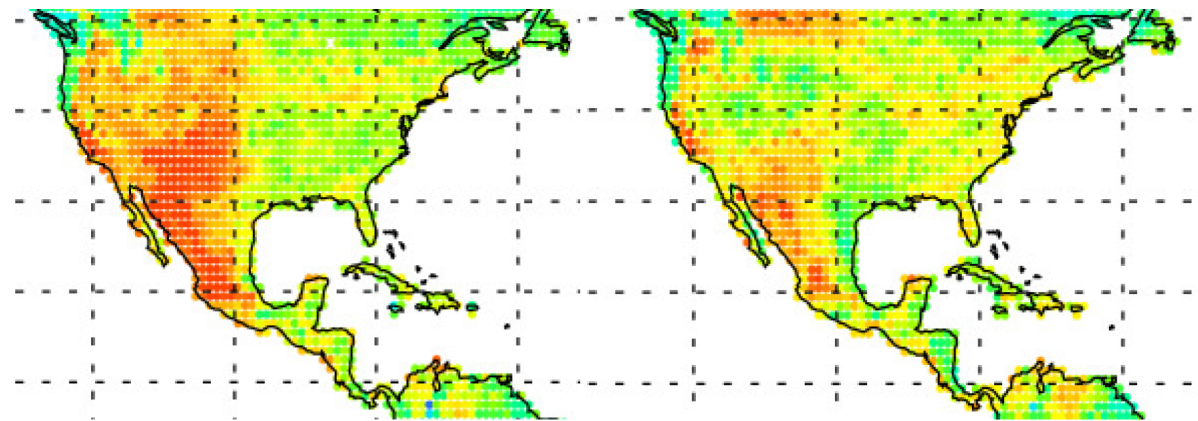

(a)

(b)

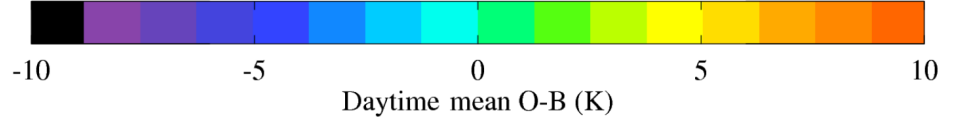

Figure 1. UM surface temperature biases (O-B) compared to IASI 1D-VAR retrievals for the North American continent during (a) GA/L3.1, May 2013, and (b) GA/L6.1_17km_static, May 2015.

is reflected. This brings the modelled bare soil cover fractions closer to the observed fractions of $63 \%$ for Lucky Hills Shrubland and $50 \%$ for Santa Rita Mesquite (Scott et al., 2015). However, at the two grassland sites, Kendall Grassland and Santa Rita Grassland, there was a reduction in bare soil fractional cover between GA/L3.1 and US2.2_ConfigA. The lower cover fraction at the grassland sites is maintained in all GA/L6.1_17km configurations. At the Kendall Grassland site, for example, the bare soil fraction is decreased from 0.26 (GA/L3.1) to 0.20 (US2.2_ConfigA-D), and at Santa Rita Grassland a similar decrease from 0.16 (GA/L3.1) to 0.10 (US2.2_ConfigA-D) is reflected. This is in contrast with the observed fractions of $60 \%$ for Kendall Grassland and $45 \%$ for Santa Rita Grassland (Scott et al., 2015).

The trend observed suggests that land surface warming can be attributed to both the revised bare soil roughness lengths and increased fraction of bare soil for the shrubland sites, whereas at the grassland sites a decrease in bare soil fractional cover appears to have a cooling affect that offsets the warming associated with the updated roughness length parameterisation.

In US2.2_ConfigB, the Lucky Hills site is seen to warm too strongly compared with the three other eddy-covariance sites. The bare soil emissivity was reduced to 0.90 in US2.2_ConfigB, which acts to reduce the upwelling longwave radiation at the surface and leads to warming of surface temperatures at all four sites. At Lucky Hills, a warm surface temperature bias develops with respect to Terra C6 (4.6 $\pm 4.5 \mathrm{~K}$ in 2014) and Aqua C6 (1.5 $\pm 2.6 \mathrm{~K}$ in 2014). The IRT measurements located at Lucky Hills support the development of the warm bias $(0.6 \pm 5.4 \mathrm{~K}$ in 2013 ; $1.4 \pm 2.6 \mathrm{~K}$ in 2015). Lucky Hills has the largest bare soil fraction of the four eddy-covariance sites; therefore, a greater change as a result of the revised bare soil emissivity is expected at this site. Although too much warming is seen at Lucky Hills, the revised emissivity leads to improvements in the surface temperature bias at the other three eddy-covariance sites.

The GA/L6.1 and US2.2 configurations use the same set of bare soil parameters (same emissivity, $z_{\mathrm{OH}} / z_{\mathrm{OM}}$ and zoM); hence, the main difference between configurations from the land perspective is the resolution of the configuration. In GA/L6.1_17km_static (2015; Fig. 3, row 3), the warming of the land surface that was seen in the US2.2_ConfigB is reflected in the global configuration. LST biases in GA/L6.1_17km_static at the two shrubland sites are reduced by $8-9 \mathrm{~K}$ with respect to Terra, and $3-5 \mathrm{~K}$ with respect to Aqua compared with GA/L3.1. The IRT measurements support the improved LST biases between the two global configurations. For example, at Lucky Hills, a reduction in the model bias from $-9.0 \pm 3.7 \mathrm{~K}(\mathrm{GA} / \mathrm{L} 3.1,2013)$ to $-2.7 \pm 2.46 \mathrm{~K}$ (GA/L6.1_17km_static, 2015) was found with respect to the IRT. The same trend is observed for Kendall Grassland: the bias is reduced from $-7.5 \pm 3.2 \mathrm{~K}(\mathrm{GA} / \mathrm{L} 3.1$, $2013)$ to $0.15 \pm 2.4 \mathrm{~K}$ (GA/L6.1_17km_static, 2015). The LST bias in all GA/L6.1 configurations is generally smaller with respect to Terra than with respect to Aqua, whereas the reverse was true for GA/L3.1. This trend supports the previously described improved phase of the LST diurnal cycle.

The biases are generally larger in GA/L6.1_17km_VarBC/US2.2_ConfigD (2016, 2017) than in GA/L6.1_17km_static /US2.2_ConfigC (2015). This step change is coincident with a change in the bias correction scheme for satellite radiances from a static scheme to VarBC, between 2015 (GA/L6.1_17km_static) and 2016 (GA/L6.1_17km_VarBC). It could be expected that a change to the treatment of the bias correction could result in a different model climatology which consequently influences the magnitude of the surface temperature bias as was found for the model humidity field (Cameron and Bell, 2018). The magnitude of the biases with GA/L6.1_17km_VarBC are still improved compared with GA/L3.1_25km_static, even 

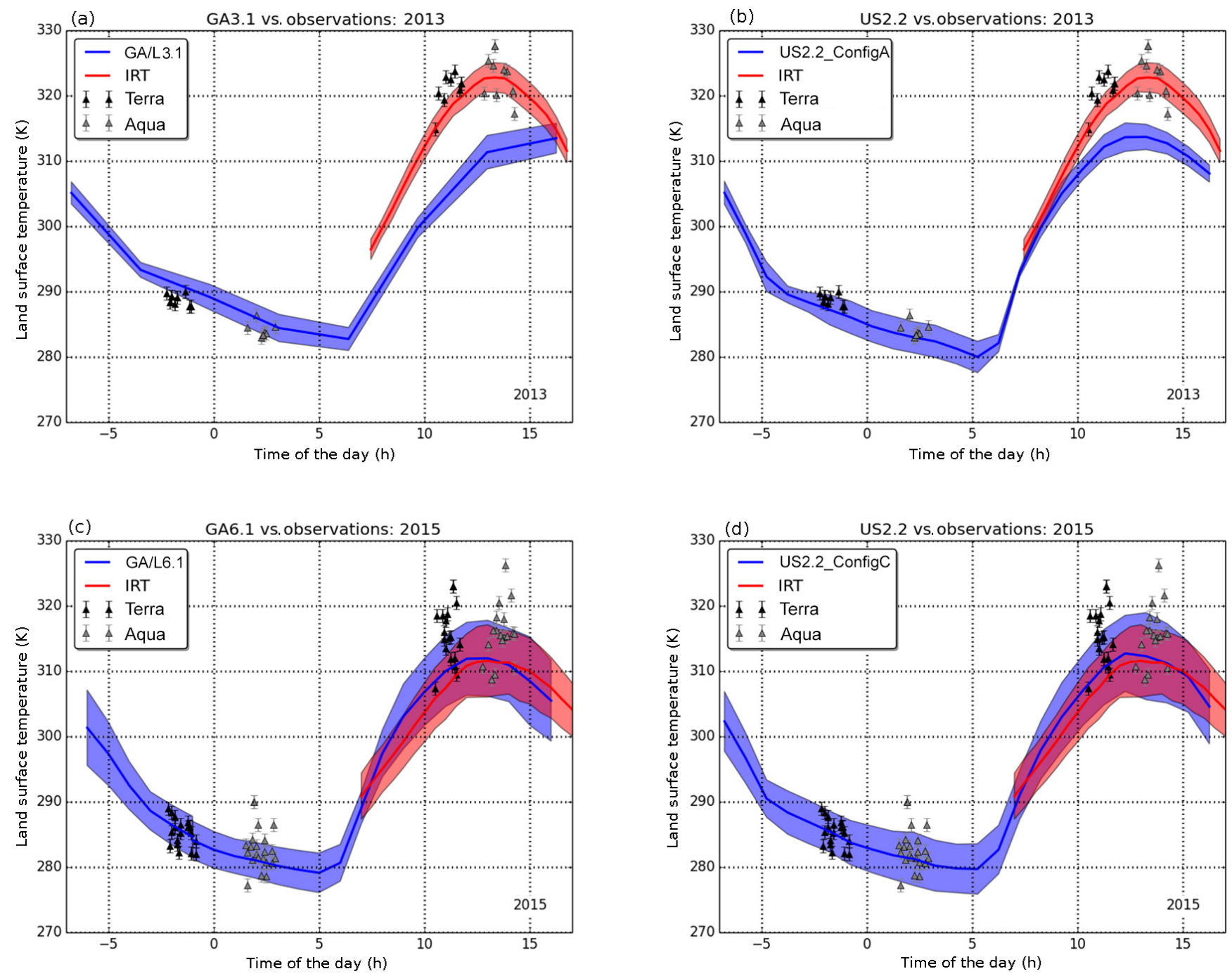

Figure 2. Diurnal cycles of surface temperature at Kendall Grassland (red) observed from IRT measurements compared with (blue) UM configurations from (a) GA/L3.1; (b) US2.2_ConfigA; (c) GA/L6.1; and (d) US2.2_ConfigC. Black triangles denote TERRA LST retrievals, and grey triangle represent AQUA LST retrievals. Time is shown using Mountain Standard Time (MST). Please note that the IRT measurements have only been plotted from 06:00 to 18:00 MST.

though there appears to be a degradation when compared with GA/L6.1_17km_static.

In 2018 it can be seen that the US2.2_ConfigE has a larger cold LST biases compared with GA/L6.1_10km_VarBC, and it is the only year in our analysis where the global configuration out-performs the higher-resolution US2.2 configuration. The GA/L6.1_10km_VarBC global configuration has an upgraded horizontal resolution of $10 \mathrm{~km}$, and this exhibits an increase in the resolution of the surface fractional cover land surface ancillary. At all four eddy-covariance sites there is an increase in the shrub and bare soil cover fractions, and an associated decrease in the total grass fraction; again, this acts to increase the sparsity of the vegetation cover and improves the model representation of the surface heterogeneity.
US2.2_ConfigE uses the ESA LC_CCI surface fractional cover dataset rather than the IGBP surface fractional cover dataset, and the trend observed suggests there is a degradation in the land surface temperature bias at all four sites relative to US2.2_ConfigA-D. The mechanism for the poorer performance will be discussed more fully in the following section.

Of the four eddy-covariance sites evaluated in this study, the least improvement is seen for the Santa Rita Grassland site across the 6-year analysis period. At Santa Rita Grassland the model LST biases with respect to Aqua are generally greater than $4-5 \mathrm{~K}$ for all configurations. In the experimental domain in south-eastern Arizona, the dominant vegetation type is shrubland, and for this reason it could be expected that the land surface ancillaries for the grassland sites, despite any 

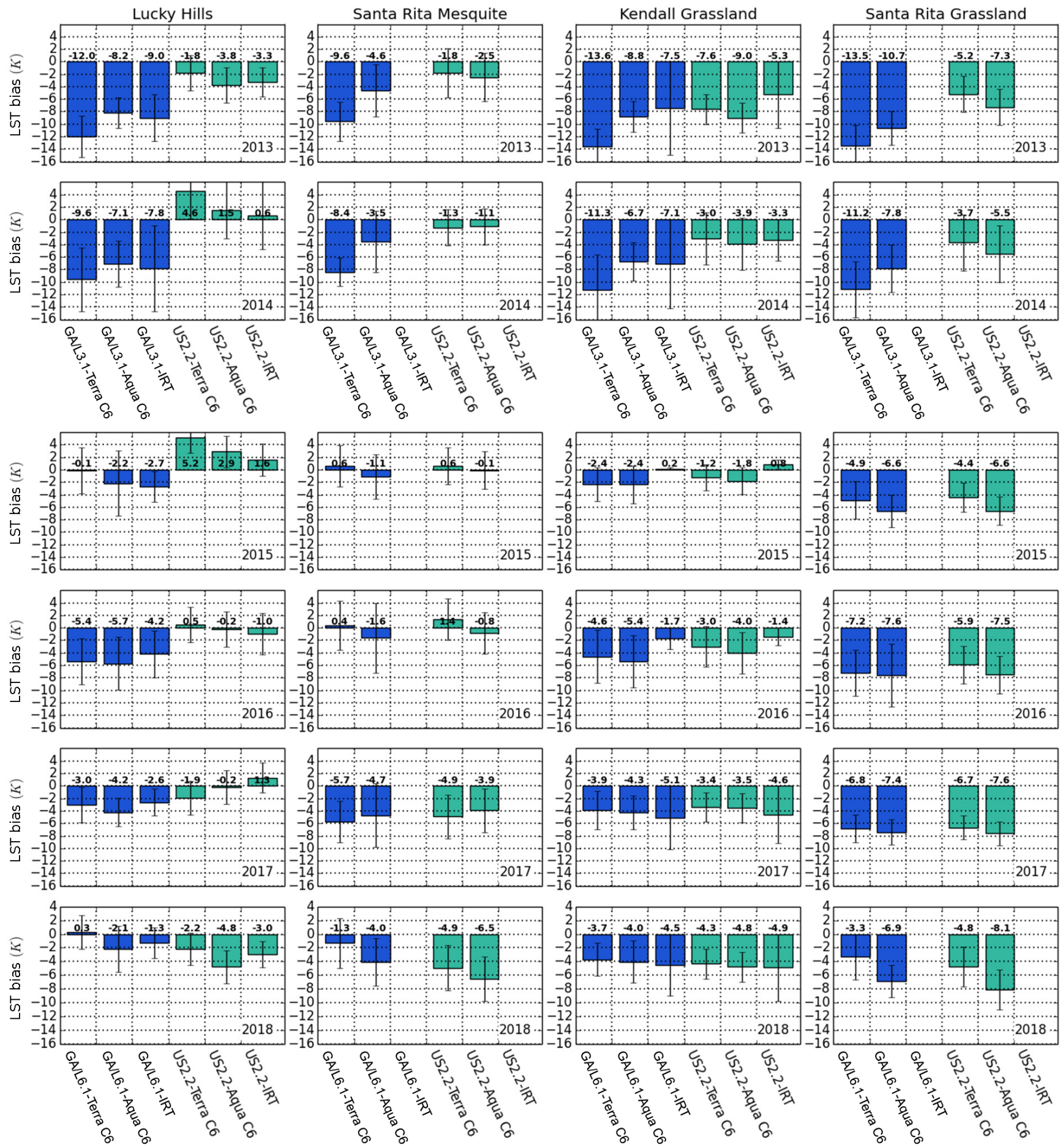

Figure 3. Daytime LST biases from the online UM configurations compared with MODIS C6 Terra and Aqua LST retrievals at the four eddy-covariance flux sites: Lucky Hills, Santa Rita Mesquite, Kendall Grassland and Santa Rita Grassland. The GA/L3.1 configurations (2013, 2014), the GA/L6.1 configurations (GA/L6.1_17km_static: 2015; GA/L6.1_17km_VarBC: 2016, 2017; and GA/L6.1_10km_VarBC: 2018) are shown in blue. The US2.2 configuration is shown in cyan. The LST evaluation was performed for 6 years: 2013 (row 1), 2014 (row 2), 2015 (row 3), 2016 (row 4), 2017 (row 5) and 2018 (row 6). 
differences in model resolution, are not as well represented as for the shrubland sites. The Santa Rita Mesquite site, in contrast, has surface temperatures biases which are below $2 \mathrm{~K}$ during 2015 and 2016, and could therefore be considered small enough to be suitable for data assimilation purposes.

As discussed in the methodology, it has been shown in the literature that MODIS C5 retrievals underestimate LST by more than $3 \mathrm{~K}$ for particular bare soil/sand sites (Wan, 2014); therefore, it was important to evaluate MODIS C5 and MODIS C6 in order to access the impact on the magnitude of the model biases. We found the different collections have minimal impact on the magnitude of the model biases (not shown). For the US2.2_ConfigA, the difference in the daytime biases is $0.9 \mathrm{~K}$, and the difference is smaller for subsequent years: $0.4 \mathrm{~K}$ in 2014 (US2.2_ConfigB) and $0.1 \mathrm{~K}$ from 2015 (US2.2_ConfigC). It was also found that the grassland sites, particularly Santa Rita Grassland, have a larger difference between the two collections $(1.5 \mathrm{~K}$ smaller for the C6 retrieval) than the shrubland sites. Furthermore, the difference between the two collections was found to be of a similar magnitude for the night-time retrievals, and is smaller than the overall variability in the night-time bias. It is important to recognise that the impacts of the retrieval algorithm are minimal when compared with the magnitude of the model biases being considered in this study.

Variability of surface temperatures could arise due to variability in cloud cover or soil moisture. In this study we consider only clear-sky situations; both the model and observational datasets have been screened to remove cloud contamination, which suggests that soil moisture variability between the analysis years could be a factor for investigation. Point-scale measurements of volumetric soil moisture at the eddy-covariance sites are made at depths of 5 and $15 \mathrm{~cm}$. A 6year multi-year mean soil moisture for each site and at each soil depth was calculated, and was used to calculate a soil moisture anomaly. At both sites, the volumetric soil moisture in May is less than $0.05 \mathrm{~kg} \mathrm{~m}^{-2}\left(0.10 \mathrm{~kg} \mathrm{~m}^{-2}\right)$ at $5 \mathrm{~cm}$ $(15 \mathrm{~cm})$ for all years in the evaluation. The in situ volumetric soil moisture measurements suggest that the moisture levels were almost always exhausted for each May analysis period; therefore, it is unlikely that there was sufficient soil moisture to impact on surface temperature variability.

In support of the eddy-covariance measurements, monthly $0.5^{\circ} \times 0.5^{\circ}$ soil moisture and soil moisture anomaly product from the Climate Prediction Center (Fan et al., 2004) were used to assess the larger-scale trends in soil moisture in south-eastern Arizona. The soil moisture anomaly product indicates that May 2013 and 2014 were anomalously dry $(-20$ to $-40 \mathrm{~mm})$ for an extensive region of the western US, May 2015 had a neutral soil moisture anomaly, May 2016 and 2017 had localised dry regions confined within Arizona, and May 2018 was anomalously dry $(-80 \mathrm{~mm})$ for an extensive region of the western US.

\subsection{Correlation of LST biases with model orography and surface heterogeneity}

The LST biases were initially evaluated for the model diurnal cycle, and then extended to attribute observed trends in LST biases to changes to model parameters for a range of UM model configurations at four eddy-covariance flux sites. The discussion going forward will centre on a domain of $31.25-32.25^{\circ} \mathrm{N}$ and $69.0-71.5^{\circ} \mathrm{W}$ in south-eastern Arizona in order to understand the spatial distribution of the surface temperature biases, and the mechanisms which give rise to the spatial distributions. The domain includes the San Pedro Basin, Sulfur Springs Valley and San Simon Valley, consisting of shrublands, grasslands and riparian surfaces, as well as isolated, forested mountain ranges. The domain is heterogeneous in terms of surface cover and orographic slope and aspect with many model grid boxes and MODIS pixels including both craggy and forested or shrubland terrain within them.

Figure 4a shows the US2.2_ConfigA-E orography for the study domain. The figure demonstrates the complex terrain in the region with low-lying ground in the north-west of the domain, numerous areas of mountainous terrain including both to the east and west of the Kendall Grassland and Lucky Hills with the highest mountain range of Chiricahua Mountains to the east $\left(31.8^{\circ} \mathrm{N}, 70.7^{\circ} \mathrm{W}\right)$. The solar radiation reaching the surface is not considered to be uniform, and the absorption of solar radiation is highly dependent on local orography such as the orography slope and aspect (Manners et al., 2012). Figure $4 \mathrm{~b}$ and $\mathrm{c}$ present the respective $x$ component and $y$ component of the orographic slope which shows that the orography in this region is generally aligned in a northsouth direction.

Firstly, we will investigate the correlation between the LST biases with the orographic slope. Our hypothesis is that northern and western-facing slopes of mountain ranges would have a shorter or delayed diurnal cycle due to reduced shortwave absorption at the surface, and that this could contribute to the spatial distribution of the LST bias. A linear least-squares regression is performed between the LST biases and the modelled orography (and surface fractional cover), and a Pearson product-moment correlation coefficient is applied to measure the strength and direction of the linear relationship between two variables.

Figure 5a shows the spatial distribution of daytime LST biases between MODIS Terra (1755Z) Collection 6 and the US2.2_ConfigA on 13 May 2013. This example was chosen to highlight typical LST biases seen during the daytime in cloud-free conditions. The mean LST bias with respect to the MODIS Collection 6 (Collection 5) is $-7.9 \pm 3.9 \mathrm{~K}$ $(-7.8 \pm 3.7 \mathrm{~K})$. Figure 5 highlights the advantage of using the $1 \mathrm{~km}$ resolution LST from MODIS compared with the IASI 1D-Var retrievals presented in Fig. 1 to examine the biases. There is significant variability in the distribution of bias with localised regions of warm and cold LST bias which 

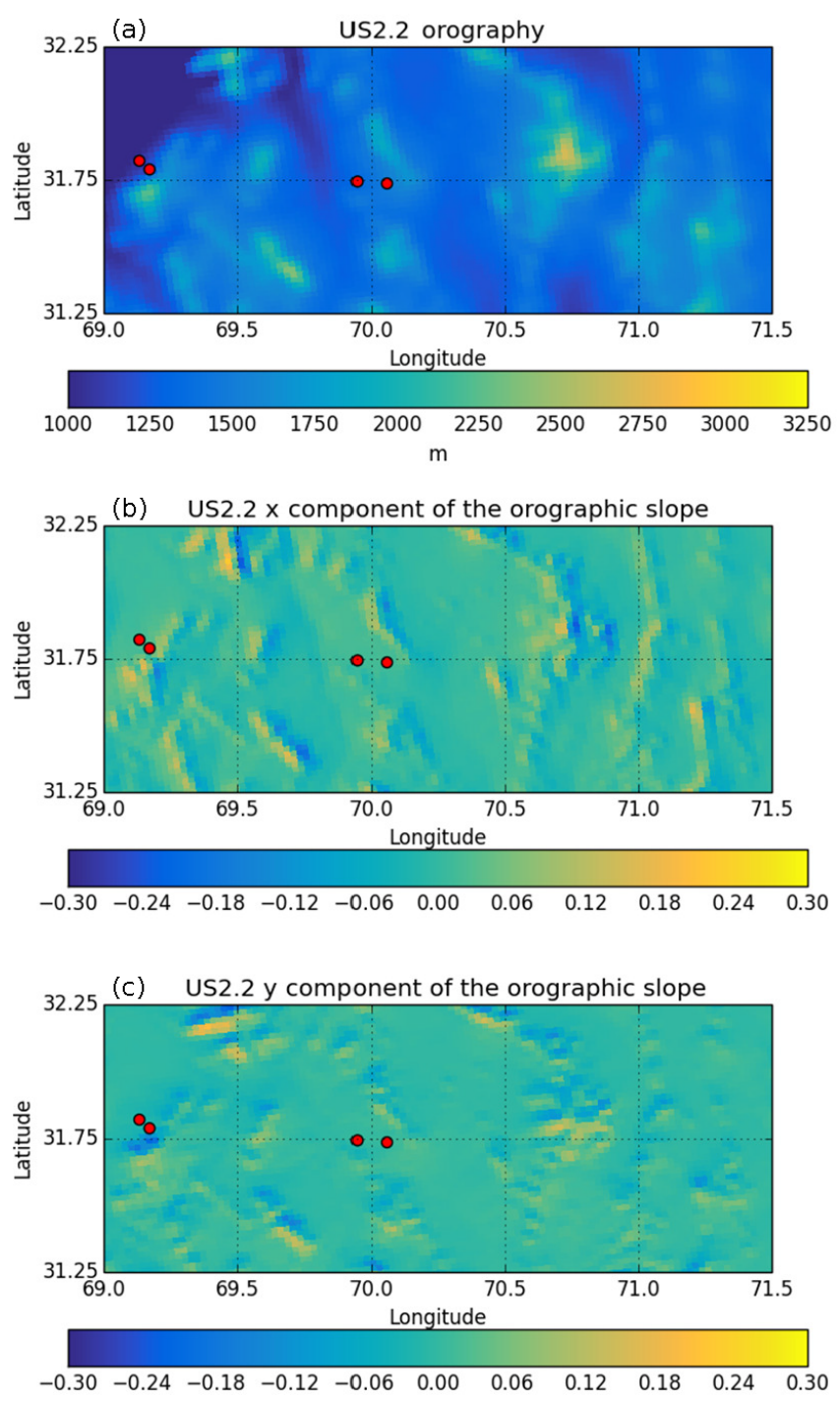

Figure 4. (a) Model orography for the US2.2 configuration. (b) US2. $2 x$ component of the orographic slope, where negative values indicate easterly facing slopes, and positive values indicate westerly facing slopes. (c) US2.2 $y$ component of the orographic slope, where negative values indicate northerly facing slopes, and positive values indicate southerly facing slopes. The red dots represent Lucky Hills $\left(31.75^{\circ} \mathrm{N}, 110.05^{\circ} \mathrm{W}\right)$, Kendall Grassland $\left(31.73^{\circ} \mathrm{N}, 109.94^{\circ} \mathrm{W}\right)$, Santa Rita Mesquite $\left(31.82^{\circ} \mathrm{N}, 110.87^{\circ} \mathrm{W}\right)$ and Santa Rita Grassland $\left(31.79^{\circ} \mathrm{N}, 110.83^{\circ} \mathrm{W}\right)$.

would not be evident using a coarser retrieval. Secondly, we will examine correlations between the surface heterogeneity in terms of the US2.2 surface fractional cover and the spatial distributions of the LST biases.

Figure $5 \mathrm{~b}$ presents the spatial distribution of the combined IGBP total grass fraction and the IGBP shrub fraction in the study domain, and Fig. 5c shows the spatial distribution of the IGBP bare soil cover fraction. We will investigate the coefficients of correlation between the LST biases and the vegetation and bare soil cover fractions represented in the US2.2_ConfigA-D surface fractional cover ancillary dataset.

Figure $5 \mathrm{~d}-\mathrm{f}$ presents the equivalent for the new ESA LC_CCI surface fractional cover introduced into the US2.2_ConfigE in 2018. Figure 5d shows the spatial distribution of daytime LST biases between MODIS Terra (1825Z) Collection 6 and the US2.2_ConfigE on 30 May 2018. The mean LST bias with respect to MODIS Collection 6 is $-7.6 \pm 3.3 \mathrm{~K}$. The mean LST bias for the domain is not significantly different to that seen in Fig. 5a, although the spatial pattern is different, with localised cold and warm LST bias regions in different locations. This is predominantly due to a redistribution of the surface fractional cover in IGBP and the ESA LC_CCI datasets. Figure 5e presents the ESA LC_CCI spatial distribution of the total grass fractions and shrub fractions, and Fig. 5f shows the ESA LC_CCI spatial distribution of the bare soil fraction. The ESA LC_CCI reduces the total grass fractional cover and the bare soil fractional cover, and increases the shrub fraction across the domain. This results in a closed shrub vegetation class. The ESA LC_CCI degrades the representation of the semi-arid ecosystem, in particular the representation of the bare soil cover fraction, which is reduced to $15 \%-20 \%$, and is significantly below the observed fractions for this region (Scott et al., 2015).

The area average May mean surface temperature bias for the US2.2 for the study region for the 6-year analysis period has been calculated and presented in Fig. 6a. For all configurations the night-time bias was less than $2.8 \mathrm{~K}$, and suggests an improvement in the night-time bias between 2013 and 2018. The daytime biases are largest for 2013 and are progressively reduced between 2013 (US2.2_ConfigA) and 2015 (US2.2_ConfigC) from -8.2 $4.4 \mathrm{~K}$ to $-5.9 \pm 4.2 \mathrm{~K}$ (with respect to MODIS Collection 6). In 2016 (US2.2_ConfigD), 2017 (US2.2_ConfigD) and 2018 (US2.2_ConfigE) the bias in the model increases to $-7.2 \pm 4.7 \mathrm{~K},-7.4 \pm 4.3 \mathrm{~K}$ and $-7.6 \pm 3.3 \mathrm{~K}$, respectively. This follows the same trend seen at the four eddy-covariance flux sites.

All data presented in Fig. 6a have been cloud-screened in the US2.2 configuration and for the MODIS overpasses. The impact of model cloud-clearing of the US2.2 has been assessed based on a threshold of total cloud cover greater than 0.1 (as described in Sect. 2.4); model cloud-clearing increases night-time biases by $0.2-0.4 \mathrm{~K}$, and reduces the absolute daytime biases by between 0.3 and $0.5 \mathrm{~K}$. Figure $6 \mathrm{a}$ presents the domain average LST bias using both MODIS C5 and C6 retrievals. There is a marginal colder bias with the MODIS Collection 6 which is in the order of $0.5-0.6 \mathrm{~K}$ in 2013-2014 and less than $0.1 \mathrm{~K}$ in 2015 and 2016. The impact of the two MODIS collections on the correlation coefficients is minimal, and only Collection 6 is presented.

The coefficients of correlation between the LST bias and the $x$ component and the $y$ component of the orographic slope have been calculated for the 6-year analysis period and 

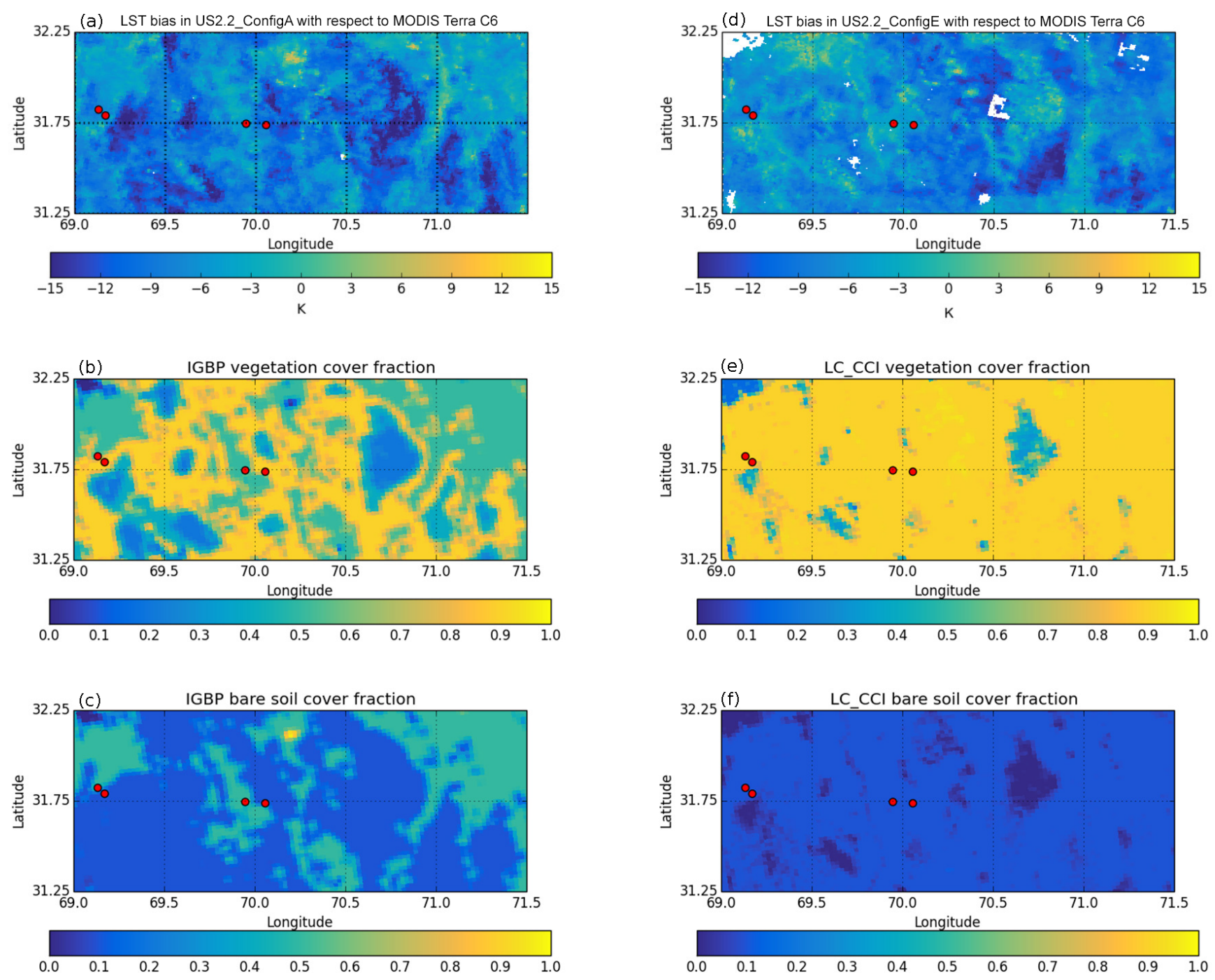

Figure 5. (a) Spatial distribution of surface temperature biases in the US2.2_ConfigA with respect to MODIS Terra Collection 6 on 13 May 2013. (b) The IGBP total grass (C3 and C4) and shrub cover fraction for the US2.2 configuration. (c) The IGBP bare soil cover fraction for the US2.2 configuration. (d) Spatial distribution of surface temperature biases in the US2.2_ConfigD with respect to MODIS Terra Collection 6 on 30 May 2018. (e) The LC_CCI total grass (C3 and C4) and shrub cover fraction for the US2.2 configuration. (f) Bare soil cover fraction for the US2.2 configuration. Red dots represent Lucky Hills $\left(31.75^{\circ} \mathrm{N}, 110.05^{\circ} \mathrm{W}\right)$, Kendall Grassland $\left(31.73^{\circ} \mathrm{N}, 109.94^{\circ} \mathrm{W}\right)$, Santa Rita Mesquite $\left(31.82^{\circ} \mathrm{N}, 110.87^{\circ} \mathrm{W}\right)$ and Santa Rita Grassland $\left(31.79^{\circ} \mathrm{N}, 110.83^{\circ} \mathrm{W}\right)$.

are presented in Fig. $6 \mathrm{~b}$ and c, respectively. The solar illumination geometry of orography changes as a function of time of day, whereas the remotely sensed LST is a directional variable with each satellite platform (Terra and Aqua) and maintains the same angle with respect to the sun. Each platform measures a similar illumination geometry on each overpass; therefore, the coefficients of correlation are calculated separately for the Terra and Aqua retrievals in Fig. 6b and $\mathrm{c}$. The night-time coefficients of correlation have a value of \pm 0.2 which indicates that there is a relationship between the two variables, but it is weak and likely insignificant. For the $x$ component prior to 2018, the daytime coefficient of correlation was positively correlated with a value of $0.41 \pm 0.05$
$(0.28 \pm 0.05)$ for Aqua (Terra) retrievals; this identifies that regions of cold model LST bias are found on easterly slopes, and regions of warm model LST bias are found on westerly slopes. We find a stronger correlation between the $x$ component of the orographic slope and the LST bias for Aqua compared with Terra, whereas the difference between the two platforms was minimal for the $y$ component of the orographic slope.

The coefficients of correlation for the $y$ component of the orographic slope have weaker correlations of less than \pm 0.2 indicating there is no north-south difference in the bias, which may be because the orography in this region is generally aligned in a north-south direction. 

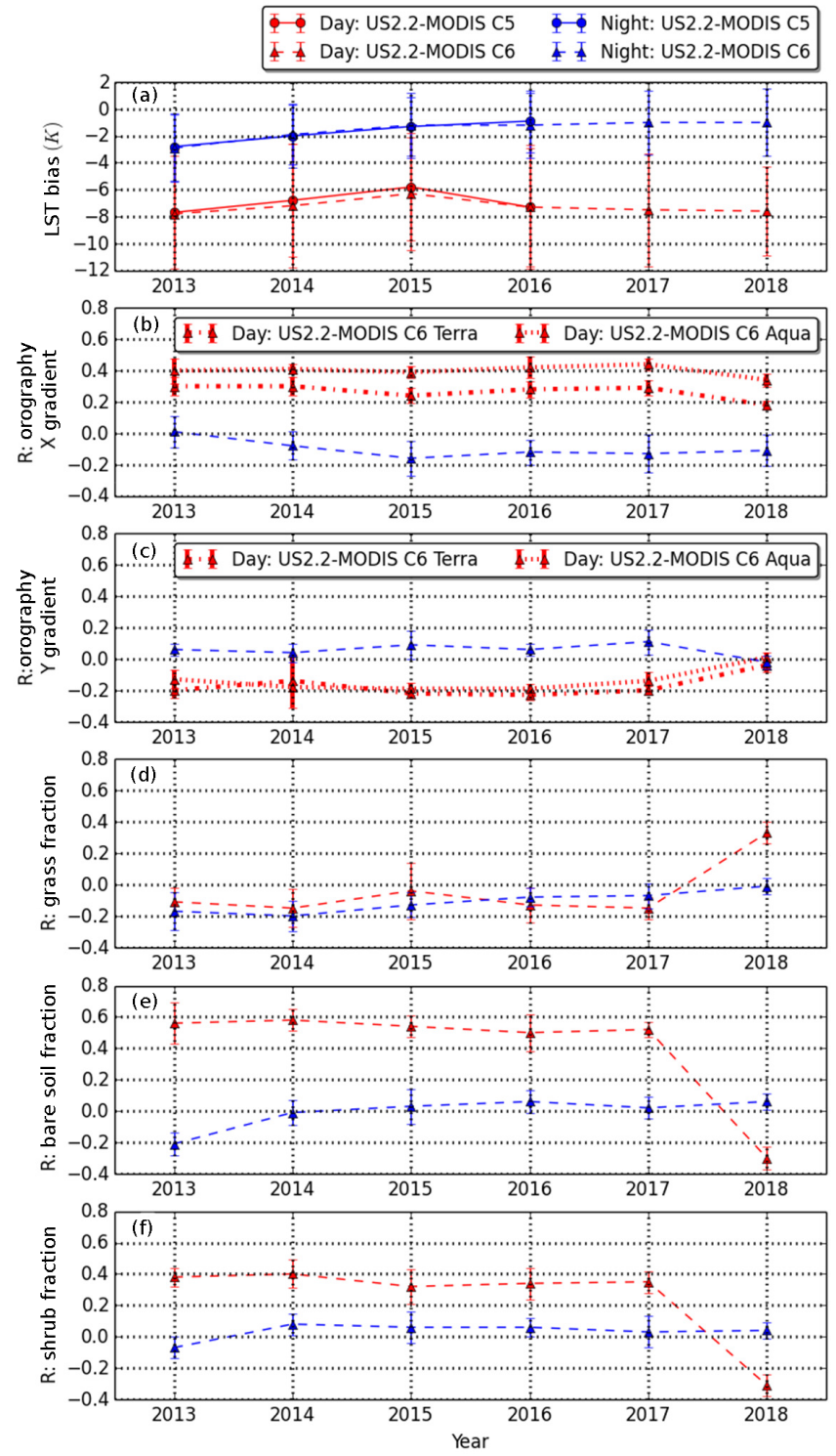

Figure 6. (a) US2.2 daytime (red) and night-time (blue) LST biases determined from MODIS Collection 5 (solid) and Collection 6 (dashed) overpasses (the average of Terra and Aqua retrievals) acquired during the May 2013-2018 period. The coefficient of correlation $(R)$ for daytime and night-time during the May 2013-2018 period between the surface temperature bias and (b) the US2.2 $x$ component of the orographic slope, (c) the US2.2 $y$ component of the orographic slope, (d) the grass fractional cover, (e) the bare soil fractional cover, and (f) the shrub fractional cover for the US2.2 configuration.

Our analysis also finds the coefficients of correlation relative to the $y$ component of the orographic slope at the time of the Terra overpasses are larger than at the time of the Aqua overpasses (not shown). This is an expected outcome of the analysis, as the Terra overpass is before noon and northern slopes will be cooler. No significant differences were ob- served for the $x$ component of the orographic slope between the respective Terra or Aqua overpasses.

The daytime and night-time correlation coefficients presented in Fig. 6d indicate that there is a null to weak relationship ( $R$ less than -0.2 ) between the LST bias and distribution of the dominant grass vegetation from 2013 to 2017. In 2018 (US2.2_ConfigE), with the introduction of ESA LC_CCI surface fractional cover, the coefficient of correlation becomes more significant $(0.33 \pm 0.07)$.

More interesting are the correlation coefficients between the LST bias and bare soil cover fraction presented in Fig. 6e. The LST bias is seen to have a moderate correlation in 2013 2017, with the IGBP bare soil cover fraction, during the daytime. The largest correlation is for 2013 with a correlation coefficient of $0.61 \pm 0.08$; this is also associated with the largest mean surface temperature bias of the 6-year analysis. From 2014 to 2017, in configurations also using the IGBP surface fractional cover, the correlation coefficients remain statistically significant with a range of $0.49 \pm 0.05$ to $0.57 \pm 0.13$. The correlation coefficients for the daytime overpasses suggest a moderately strong relationship and that regions with a cold LST bias are associated with low bare soil cover fractions. At night the LST bias is weakly correlated $(-0.21 \pm 0.06$ in 2013) with the bare soil cover fraction - the correlation not significantly different from zero for 2014 to 2018.

The 2013-2017 coefficients of correlation with the IGBP shrub surface fractions follow the same trend as the IGBP bare soil fractions, although with a less significant correlation $(0.36 \pm 0.09)$. Again, this suggests that the regions of cold model LST bias are additionally associated with regions with low shrub fractions $(<20 \%)$, although it is secondary to the sensitivity of the bare soil. These results indicate that sparse vegetation canopies across the study domain are not well represented by the IGBP surface fractional cover. Our findings suggest that the development of surface cover ancillary datasets for sparse canopies is necessary.

In 2018, the coefficients of correlation are weaker for both the ESA LC_CCI shrub surface fractional cover $(-0.31 \pm$ $0.04)$ and bare soil surface fractional cover $(-0.30 \pm 0.06)$ and are the opposite sign to that calculated for the IGBP surface fractional cover. As described previously, the ESA LC_CCI degrades the representation of the semi-arid ecosystem, in particular the representation of the bare soil cover fraction, by forming a closed shrub vegetation class to represent the region. The ESA LC_CCI bare soil fractions remain too low across the study domain, and this is a possible explanation as to why the mean LST bias from the $2.2 \mathrm{~km}$ model for 2018 is $-7.6 \pm 3.3 \mathrm{~K}$ and is effectively unchanged from the mean LST bias for $2013(-7.8 \pm 4.7 \mathrm{~K})$.

The coefficients of correlation with respect to the surface heterogeneity at the time of the Terra overpasses are larger than at the time of the Aqua overpasses (not shown). This is despite the LST biases not reaching a maximum until closer to the time of the Aqua overpass. This indicates that when 
the magnitude of the LST bias is at its maximum there is a competing cause to the LST bias which cannot only be fully explained by the representation of surface heterogeneity in the model.

\subsection{Evaluation of UM surface energy balance}

The total available energy at the surface is partitioned between the turbulent heat and moisture fluxes to the atmosphere, as well as the ground heat flux to the soil, all of which ultimately control the surface temperature. Eddycovariance measurements offer model verification of these surface exchange processes, and provide an opportunity to examine sources of model error by investigating components of the SEB simulated by the UM. Figure 7 presents scatterplots of observed SEB components compared with the US2.2_ConfigA SEB components for May 2013 at Kendall Grassland.

Figure 7a presents the net radiation (NR) for all-sky conditions which represents the available energy at the surface from radiation; when NR is positive there is greater incoming radiation than outgoing radiation. At night, the NR term is negative, as the net longwave radiation is dominated by the outgoing terrestrial longwave flux. A night-time overestimate in NR of $36 \mathrm{~W} \mathrm{~m}^{-2}$ is evident in the US2.2_ConfigA. The downwelling longwave radiation (LWD) is also underestimated (not shown); this suggests that the night-time NR bias is caused by too much upwelling longwave radiation, and potentially indicates that the surface emissivity is too large. This result provides motivation for a revised bare soil emissivity. Daytime biases in NR are seen to be minimal at Kendall Grassland. Daytime biases are more significant at Lucky Hills (not shown) with an underestimation in the order of $16-25 \mathrm{~W} \mathrm{~m}^{-2}$ which arises due to an underestimation of the downwelling shortwave radiation in the US2.2 configuration.

The turbulent transfer of heat and moisture towards (negative flux) or away (positive flux) from the surface within the atmosphere is represented by the sensible and latent heat fluxes, respectively. Figure $7 \mathrm{~b}$ presents a scatterplot of the observed (corrected) sensible heat flux compared with the modelled sensible heat flux, which shows a positive model bias in the sensible heat flux of $25 \mathrm{~W} \mathrm{~m}^{-2}$ and indicates that the model flux is overestimated during the local solar maximum. During the transition period from early morning into the late morning period there is an underestimate in the modelled sensible heat flux, which suggests the US2.2_ConfigA does not represent the rate of increase in the sensible heat flux seen in the observations.

The equivalent scatterplot for the latent heat flux, presented in Fig. 7c, indicates that the US2.2_ConfigA latent heat fluxes are too large. A night-time (and transition) bias of $6 \mathrm{~W} \mathrm{~m}^{-2}$, and a daytime bias of $23 \mathrm{~W} \mathrm{~m}^{-2}$ were calculated. This result was also seen for GA/L3.1, as well as for the Lucky Hills site (plots not shown). In general it was found that there is a greater overestimate in the modelled turbulent heat and moisture fluxes when compared with the measured fluxes rather than the corrected turbulent fluxes.

Finally, Fig. $7 \mathrm{~d}$ presents the measured ground heat flux compared with the modelled ground heat flux. The night-time ground heat flux is well represented by the US2.2_ConfigA; however, the transition and daytime ground heat flux is poorly simulated by the US2.2_ConfigA. Again, this result was also seen for GA/L3.1. The US2.2_ConfigA daytime maxima is underestimated by $100 \mathrm{~W} \mathrm{~m}^{-2}$ compared with the observations, although during the transition to morning and evening periods the ground heat flux is overestimated.

A delay of the onset of heating in the morning transition is evident in the observations which leads to a phase separation between the measured ground heat fluxes and the residual (NR-H-LE) (plot not shown), which possibly casts doubt on the ground heat flux measurements at Kendall Grassland. The timing of the measured ground heat flux is poorly represented, relative to the turbulent and radiant forcing, which suggests the possibility that the measurements, taken at depth, have not been correctly extrapolated to the surface. However, an alternative interpretation could be that there is shading at location of the ground heat flux plates from vegetation at the Kendall Grassland site, whereas the net radiometers are mounted above the vegetation canopy and not subject to the effects of shading; this could lead to the lag in the ground heat flux relative to the radiative forcing.

This helps explain the timing hysteresis in the corrected sensible heat flux observed in Fig. 7b, which is seen to be in the opposite direction to the ground heat flux: closure of the surface energy balance has been forced; therefore, any lag in the timing of the measured ground heat flux will propagate into the corrected sensible heat flux.

Our results indicate the models' fluxes at Kendall Grassland (and Lucky Hills) are inadequate for representing ground heat fluxes, which suggests that the excess modelled turbulent heat and moisture fluxes are compensated for by an underestimate in the modelled ground heat flux. This result indicates the partitioning of the turbulent heat and moisture fluxes to the atmosphere, and that the flux of heat to the soil are not well represented in the US2.2 (and GA/L3.1), and could contribute to the surface temperature biases evaluated in this study. A comprehensive evaluation of the surface energy balance of the Unified Model and the stand-alone JULES land surface model is necessary to understand the model errors in greater detail, although this is outside of the scope of this study.

\section{Conclusions}

A limitation of the Met Office operational data assimilation scheme is that surface-sensitive infrared hyperspectral 

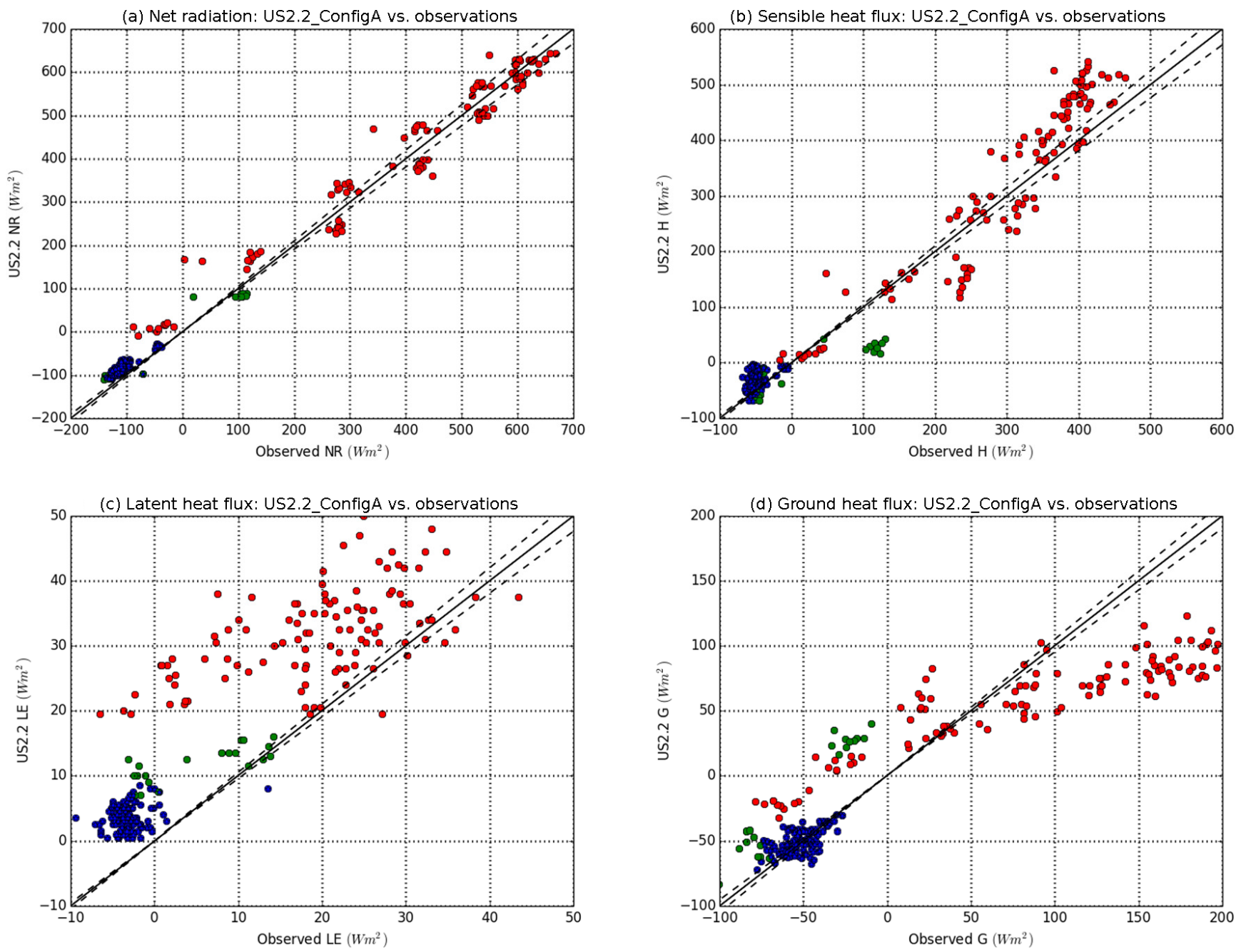

Figure 7. Scatterplots comparing the observed components of the surface energy balance with the modelled US2.2_ConfigA components of the surface energy balance at Kendall Grassland for May 2013. The panels from top to bottom are (a) net radiation, (b) (corrected) sensible heat flux, (c) (corrected) latent heat flux and (d) (measured) ground heat flux. The components of the SEB are separated into (blue) night-time (model SWD $<5 \mathrm{~W} \mathrm{~m}^{-2}$ ), (green) transition (model SWD 5-200 $\mathrm{W} \mathrm{m}^{-2}$ ) and (red) daytime (model SWD $>200 \mathrm{~W} \mathrm{~m}^{-2}$ ).

satellite sounding channels cannot be used during daytime periods where biases in the numerical weather prediction (NWP) model background land surface temperature (LST) are greater than $2 \mathrm{~K}$. The Met Office Unified Model (UM) has a significant cold bias in LSTs in semi-arid regions when compared with satellite observations. This work evaluates UM surface temperature biases for two UM global configurations, Global Atmosphere/Land 3.1 (GA/L3.1) and Global Atmosphere/Land 6.1 (GA/L6.1) and in a limited area model (LAM) at $2.2 \mathrm{~km}$ (US2.2) resolution for a study domain in south-eastern Arizona USA which coincided with the SALSTICE (Semi-Arid Land Surface Temperature and IASI Calibration Experiment) campaign.

The UM surface temperature biases for the North American continent during May, the time of maximum LST biases, were investigated using IASI 1D-VAR retrievals. GA/L3.1 gave rise to an east-west divide in the magnitude of LST biases with cold biases in excess of $-10 \mathrm{~K}$ in the south-west US, western Mexico and extending east into the Great Plains. Moderate LST biases, in the range of -4 to $-6 \mathrm{~K}$, were shown to extend into the northern US. The LST bias was found to be reduced in GA/L6.1 compared with GA/L3.1, although regional biases such as the south-west US were still prominent.

The UM surface temperature biases were examined at higher resolution using MODIS surface temperature retrievals from the Aqua and Terra platforms for an analysis period of the months of May in 2013-2018. The evaluation was in conjunction with ground-based measurements from eddycovariance flux tower sites in the Walnut Gulch Experimental Watershed and Santa Rita Experimental Range in southeastern Arizona. Examining the representation of the diur- 
nal cycle of surface temperature, it was found that biases in modelled LST were largest in the mid-morning in GA/L3.1, which indicated that GA/L3.1 struggled to capture the magnitude of the warming from the morning transition to the late morning period. The phase of the diurnal cycle of surface temperature in GA/L6.1 showed a significant improvement relative to GA/L3.1, and supported the result found relative to IASI 1D-VAR retrievals for the North American continent. The diurnal cycle in the higher-resolution US2.2 also showed that the phase of the surface temperature was improved relative to the GA/L3.1 configuration, and that it improved the timing of the initial warming during the morning transition.

The surface temperature bias response for different vegetation biomes was investigated at four eddy-covariance flux tower sites located in different land classification types. The improvement in surface temperature in the US2.2 (compared with the global configuration) was found to be greater at the two shrubland sites, Lucky Hills and Santa Rita Mesquite, compared with the two grassland sites, Kendall Grassland and Santa Rita Mesquite. Improvements at all four sites in the US2. 2 configuration was attributed to changes in the bare soil parameters including a revised bare soil emissivity and revised thermal and momentum roughness lengths for bare soil. The shrubland sites had an increase in the bare soil fractional cover associated with the increasing model resolution, which increased the sparsity of the vegetation cover, and subsequently improved the model representation of the surface heterogeneity. In contrast, at the grassland sites, there was a reduction in bare soil fractional cover.

The limitation of available water for vegetation in semiarid regions results in a very heterogeneous natural landscape, which increases the scientific challenges of representing such surface heterogeneities in land surface models. Our study examined a domain in south-eastern Arizona in order to understand the spatial distribution of the surface temperature biases, and the mechanisms which give rise to the spatial distributions. The study domain is heterogeneous, in terms of surface vegetation cover and orographic slope and aspect, with many model grid boxes including both craggy and forested or shrubland terrain. Our results highlight that there was no dominant underlying cause to the distribution of LST biases in the study domain. The LST bias was found to have a moderate correlation with the International GeosphereBiosphere Programme's (IGBP) bare soil cover fraction during the daytime and suggested that regions of cold model LST bias were associated with low bare soil cover fractions. Coefficients of correlation with the IGBP shrub surface fractions were found to follow the same trend as the IGBP bare soil fractions, although with a less significant correlation, and secondary to the sensitivity of the bare soil. The results indicate that sparse vegetation canopies are not well represented by the IGBP surface fractional cover.

Considering orography in the study domain, the daytime coefficients of correlation were positively correlated with the $x$ component of the orographic slope, which indicated that regions of cold model LST bias were found on easterly slopes and regions of warm model LST bias were found on westerly slopes. The coefficients of correlation for the $y$ component of the orographic slope were found to have weaker correlation of less than \pm 0.2 , as the orography in the study region is generally aligned in a north-south direction.

For the US2.2 configuration in 2018, the surface fractional cover ancillary used the European Space Agency's Land Cover Climate Change Initiative (ESA LC_CCI) global vegetation distribution mapped to the JULES five PFTs. The ESA LC_CCI ancillary degrades the representation of the semi-arid ecosystem in the study region, in particular the representation of the bare soil cover fraction, which was reduced to $15 \%-20 \%$, and is significantly below the observed fractions for this region (Scott et al., 2015). The ESA LC_CCI bare soil fractions were shown to be too low across the study domain, even more so than the IGBP bare soil cover fractions, and this is a possible explanation as to why the mean LST bias in the US2.2 configuration for 2018 was $-7.6 \pm 3.3 \mathrm{~K}$ and was effectively unchanged from the mean LST bias for $2013(-7.8 \pm 4.7 \mathrm{~K})$.

The US2.2 was found to be deficient in representing ground heat fluxes when compared against eddy-covariance measurements at Kendall Grassland and Lucky Hills sites. The modelled turbulent heat and moisture fluxes were overestimated compared with observations. The modelled latent heat flux was overestimated for all periods of the diurnal cycle, and the modelled sensible heat flux was overestimated during the local solar maximum. This result indicates the partitioning of the turbulent heat and moisture fluxes to the atmosphere, and that the flux of heat to the soil are not well represented in the US2.2 (and GA/L3.1) configuration, and could contribute to the surface temperature biases evaluated in this study. Our results call for a comprehensive evaluation of the SEB of the Unified Model and the stand-alone JULES land surface model in semi-arid regions.

The validation presented in this paper used ground-based and satellite measurements as well as, to a large degree, the two comparisons generate comparable results considering the vast differences in the scales of the measurements. The two methods have advantages and disadvantages that complement each other; the MODIS comparisons gave a high spatial resolution representation at specific snapshots in time, whereas the eddy-covariance site measurements gave full diurnal cycles, although with very limited areal coverage. The MODIS data are conducive to geostatistical analysis, whereas the ground site data are suitable for time-series analysis. A further consideration is the disparity between the footprint size of the IRTs, radiation measurements and the ground heat flux plates relative to those of the sonic anemometers measuring the turbulent fluxes.

With recent advances in supercomputing power, performing high-resolution ensemble forecasting, for example within a research LAM such as the US2.2, is becoming viable. This will provide the opportunity to evaluate the impact of fore- 
cast uncertainty on the land surface processes, rather than only for the deterministic forecast as has been carried out in this study. The Met Office Global and Regional Ensemble Prediction System (MOGREPS) is the ensemble system that produces uncertainty information for the model configurations.

The outcomes of SALSTICE show the difficulties in producing land surface temperatures that match the current stateof-the-art satellite retrievals within our current NWP system. The unfortunate fact is that LSTs are not used to evaluate the model during model development and much of the LST information available from satellites is thrown away by the data assimilation system. Therefore, it is not surprising that the prediction of LSTs in our operational NWP suite has not improved significantly since GA/L3.1.

Code availability. Obtaining the UM. The Met Office Unified Model is available for use under licence. A number of research organisations and national meteorological services use the UM in collaboration with the Met Office to undertake basic atmospheric process research, produce forecasts, develop the UM code and build and evaluate Earth system models. For further information on how to apply for a licence see https://www.metoffice.gov.uk/research/ modelling-systems/unified-model (last access: 18 April 2019).

Obtaining JULES. JULES is available under licence free of charge. For further information on how to gain permission to use JULES for research purposes see https://jules.jchmr.org/content/ getting-started and http://jules-1sm.github.io/access_req/JULES_ access.html (both URLs were last accessed 18 April 2019).

Data availability. Data used in this paper are available at the AmeriFlux data repository (2018) (http://ameriflux.lbl.gov/).

Supplement. The supplement related to this article is available online at: https://doi.org/10.5194/gmd-12-1703-2019-supplement.

Author contributions. JKB evaluated the model simulations and wrote the paper. $\mathrm{RCH}$ was the project investigator for SALSTICE. RLS supplied eddy-covariance data. MJB and JME provided advice on the surface energy balance of the UM. MW developed the $2.2 \mathrm{~km}$ model configuration. JCT advised on the radiative transfer calculations for calculating the downwelling longwave radiation applied to the IRT dataset. All authors were involved in discussions throughout development, and all authors commented on the paper.

Competing interests. The authors declare that they have no conflict of interest.

Acknowledgements. This work was funded by the Met Office. The author would like to thank the staff at USDA-Agricultural Research Service's Southwest Watershed Research Centre for their efforts in providing the eddy-covariance data and facilitating the placement of additional sensors at Lucky Hills and Kendall Grassland within the Walnut Gulch Experimental Watershed.

Review statement. This paper was edited by Juan Antonio Añel and reviewed by Larry K. Berg and one anonymous referee.

\section{References}

AmeriFlux data repository: AmeriFlux data at half-hourly resolution, available at: http://ameriflux.lbl.gov/, last access: 17 July 2018.

Best, M. J., Pryor, M., Clark, D. B., Rooney, G. G., Essery, R. L. H., Ménard, C. B., Edwards, J. M., Hendry, M. A., Porson, A., Gedney, N., Mercado, L. M., Sitch, S., Blyth, E., Boucher, O., Cox, P. M., Grimmond, C. S. B., and Harding, R. J.: The Joint UK Land Environment Simulator (JULES), model description Part 1: Energy and water fluxes, Geosci. Model Dev., 4, 677-699, https://doi.org/10.5194/gmd-4-677-2011, 2011.

Bugbee, B., Droter, M., Monje, O., and Tanner, B.: Evaluation and modification of commercial infrared transducers for leaf temperature measurement, Adv. Space Res., 22, 1425-1434, 1998.

Cameron, J. and Bell, W.: The testing and implementation of variational bias correction (VarBC) in the global model at the Met Office, Weather Science Technical Report No: 63, available at: https://www.metoffice.gov.uk/research/library-and-archive/ publications/science/weather-science-technical-reports/ (last access: 18 April 2019), 2018.

Candy, B., Saunders, R. W., Ghent, D., and Bulgin, C. E.: The impact of satellite-derived land surface temperatures on numerical weather prediction analyses and forecasts, J. Geophys. Res.Atmos., 122, https://doi.org/10.1002/2016JD026417, 2017.

Cardinali, C.: Monitoring the observation impact on the short-range forecast, Q. J. Roy. Meteor. Soc., 135, 239-250, 2009.

Castelli, F., Entekhabi, D., and Caporali, E.: Estimation of surface heat flux and an index of soil moisture using adjoint-state surface energy balance, Water Resour. Res., 35, 3115-3125, 1999.

Chen, F. and Zhang, Y.: On the coupling strength between the land surface and the atmosphere: From viewpoint of surface exchange coefficients, Geophys. Res. Lett., 36, L10404, https://doi.org/10.1029/2009GL037980, 2009.

Clark, D. B., Mercado, L. M., Sitch, S., Jones, C. D., Gedney, N., Best, M. J., Pryor, M., Rooney, G. G., Essery, R. L. H., Blyth, E., Boucher, O., Harding, R. J., Huntingford, C., and Cox, P. M.: The Joint UK Land Environment Simulator (JULES), model description - Part 2: Carbon fluxes and vegetation dynamics, Geosci. Model Dev., 4, 701-722, https://doi.org/10.5194/gmd-4701-2011, 2011.

Coll, C., Caselles, V., Galve, J. M., Valor, E., Niclos, R., Sanchez, J. M., and Rivas, R.: Ground measurements for the validation of land surface temperatures derived from AATSR and MODIS data, Remote Sens. Environ., 97, 288-300, 2005.

Coops, N. C., Duro, D. C., Wulder, M. A., and Han, T.: Estimating afternoon MODIS land surface temperatures (LST) based on morning MODIS overpass, location and elevation information, Int. J. Remote Sens., 28, 2391-2396, 2007. 
Davies, T.: Lateral boundary conditions for limited area models, Q. J. Roy. Meteor. Soc., 140, 185-196, 2014.

Davies, T., Cullen, M. J. P., Malcolm, A. J., Mawson, M. H., Staniforth, A., White, A. A., and Wood, N.: A new dynamical core for the Met Office's global and regional modelling of the atmosphere, Q. J. Roy. Meteor. Soc., 131, 1759-1782, 2005.

Dee, D. P., Uppala, S. M., Simmons, A. J., Berrisford, P., Poli, P., Kobayashi, S., Andrae, U., Balmaseda, M. A., Balsamo, G., Bauer, P., Bechtold, P., Beljaars, A. C., van de Berg, L., Bidlot, J., Bormann, N., Delsol, C., Dragani, R., Fuentes, M., Geer, A. J., Haimberger, L., Healy, S. B., Hersbach, H., Hólm, E. V., Isaksen, L., Kållberg, P., Köhler, M., Matricardi, M., McNally, A. P., Monge-Sanz, B. M., Morcrette, J., Park, B., Peubey, C., de Rosnay, P., Tavolato, C., Thépaut, J., and Vitart, F.: The ERA-Interim reanalysis: configuration and performance of the data assimilation system, Q. J. Roy. Meteor. Soc., 137, 553-597, https://doi.org/10.1002/qj.828, 2011.

Dharssi, I., Bovis, K. J., Macpherson, B., and Jones, C. P.: Operational assimilation of ASCAT surface soil wetness at the Met Office, Hydrol. Earth Syst. Sci., 15, 2729-2746, https://doi.org/10.5194/hess-15-2729-2011, 2011.

Dickinson, R. E., Hendersin-Sellers, A., Rosenzweig, C., and Sellers, P. J.: Evapotranspiration models with canopy resistance for use in climate models: A review, Agr. Forest Meteorol., 54, 373388, 1991.

Duffour, C., Lagouarde, J. P., Olioso, A., Demarty, J., and Roujean, J. L.: Driving factors of the directional variability of thermal infrared signal in temperate regions, Remote Sens. Environ., 177, https://doi.org/10.1016/j.rse.2016.02.024, 2016.

Edwards, J. M.: Assessment of Met Office forecasting models with SEVIRI LSTs, Proceedings of the 4th LSA SAF User Training Workshop, 15-17 November 2010, Météo-France, Toulouse, France, 2010.

Emmerich, W. E. and Verdugo, C. L.: Long-term carbon dioxide and water flux database Walnut Gulch Experimental Watershed, Arizona, United States, Water Resour. Res., 44, W05S09, https://doi.org/10.1029/2006WR005693, 2008.

English, S. J., Renshaw, R. J., Dibben, P. C., Smith, A. J., Rayer, P. J., Poulsen, C., Saunders, F. W., and Eyre, J. R.: A comparison of the impact of TOVS and ATOVS satellite sounding data on the accuracy of numerical weather forecasts, Q. J. Roy. Meteor. Soc., 126, 2911-2931, 2000.

Ermida, S. L., Trigo, I. F., Dacamara, C. C., Göttsche, F. M., Olesen, F. S., and Hulley, G.: Validation of remotely sensed surface temperature over an oak woodland landscape - The problem of viewing and illumination geometries, Remote Sens. Environ., 148, 16-27, 2014.

Essery, R. L. H., Best, M. J., Betts, R. A., Cox, P. M., and Taylor, C. M.: Explicit representation of subgrid heterogeneity in a GCM land surface scheme, J. Hydrometeorol., 4, 530-543, 2003.

Fan, Y. and van den Dool, H.: Climate Prediction Center global monthly soil moisture data set at $0.5^{\circ}$ resolution for 1948 to present, J. Geophys. Res., 109, D10102, https://doi.org/10.1029/2003JD004345, 2004.

Fiebrich, C. A., Martinez, J. E., Brotzge, J. A., and Basara, J. B.: The Oklahoma Mesonet's skin temperature network, J. Atmos. Ocean. Tech., 20, 1496-1504, 2003.

Foken, T.: The energy balance closure problem: an overview, Ecol. Appl., 18, 1351-1367, 2008.
Fry, J., Xian, G., Jin, S., Dewitz, J., Homer, C., Yang, L., Barnes, C., Herold, N., and Wickham, J.: Completion of the $2006 \mathrm{Na}$ tional Land Cover Database for the Conterminous United States, Photogramm. Eng. Rem. S., 77, 858-864, 2011.

Gentine, P., Entekhabi, D., and Heusinkveld, B.: Systematic errors in ground heat flux estimation and their correction, Water Resour. Res., 48, W09541, https://doi.org/10.1029/2010WR010203, 2012.

Ghent, D., Dodd, E., Trigo, I., Pires, A., Sardou, O., Bruniquel, J., Gottsche, F., Martin, M., Prigent, C., Jimenez, C., and Remedios, J.: ESA DUE GlobTemperature product user guide V2, available at: http://www.globtemperature.info (last access: 11 September 2018), 2016.

Guedj, S., Karbou, F., and Rabier, F.: Land surface temperature estimation to improve the assimilation of SEVIRI radiances over land, J. Geophys. Res., 116, D14107, https://doi.org/10.1029/2011JD015776, 2011.

Hanley, K. E., Barrett, A. I., and Lean, H. W.: Simulating the 20 May 2013 Moore, Oklahoma tornado with a 10-metre gridlength NWP model, Atmos. Sci. Lett., 17, 453-461, 2016.

Harper, A. B., Cox, P. M., Friedlingstein, P., Wiltshire, A. J., Jones, C. D., Sitch, S., Mercado, L. M., Groenendijk, M., Robertson, E., Kattge, J., Bönisch, G., Atkin, O. K., Bahn, M., Cornelissen, J., Niinemets, Ü., Onipchenko, V., Peñuelas, J., Poorter, L., Reich, P. B., Soudzilovskaia, N. A., and Bodegom, P. V.: Improved representation of plant functional types and physiology in the Joint UK Land Environment Simulator (JULES v4.2) using plant trait information, Geosci. Model Dev., 9, 2415-2440, https://doi.org/10.5194/gmd-9-2415-2016, 2016.

Harris, B. A. and Kelly, G.: A satellite radiance-bias correction scheme for data assimilation, Q. J. Roy. Meteor. Soc., 127, 14531468, 2001.

Havemann, S.: The development of a fast radiative transfer model based on an empirical orthogonal functions (EOF) technique, Proc. SPIE, 6405, 64050M, https://doi.org/10.1117/12.693995, 2006.

Henderson-Sellers, A., Yang, Z., and Dickinson, R. E.: The Project for Intercomparison of Landsurface Parameterization Schemes, B. Am. Meteorol. Soc., 74, 1335-1350, https://doi.org/10.1175/15200477(1993)074<1335:TPFIOL>2.0.CO;2, 1993.

Hilton, F.: Hyperspectral Earth observation from IASI: Five years of accomplishments, B. Am. Meteorol. Soc., 93, 347-370, https://doi.org/10.1175/BAMS-D-11-00027.1, 2012.

Hu, L., Brunsell, N. A., Monaghan, A. J., Barlage, M., and Wilhelmi, O. V.: How can we use MODIS land surface temperature to validate long-term urban model simulations?, J. Geophys. Res.-Atmos., 119, 3185-3201, 2014.

Kasahara, A., Mizzi, A. P., and Donner, L. J.: Impact of Cumulus Initialization on the Spinup of Precipitation Forecasts in the Tropics, Mon. Weather Rev., 120, 1360-1380, 1992.

Kerr, Y. H., Lagouarde, J. P., Nerry, F., and Ottlé, C.: Land surface temperature retrieval techniques and applications, Thermal remote sensing in land surface processes, CRC Press, Boca Raton, Florida, 33-109, 2000.

Li, Z., Tang, B., Wu, H., Ren, H., Yan, G., Wan, Z., Trigo, I. F., and Sobrino, J.: Satellite-derived land surface temperature: Current status and perspectives, Remote Sens. Environ., 131, 14-37, 2013. 
Manners, J., Vosper, S. B., and Roberts, N.: Radiative transfer over resolved topographic features for high-resolution weather prediction, Q. J. Roy. Meteor. Soc., 138, 720-733, https://doi.org/10.1002/qj.956, 2012.

Monin, A. S. and Obukhov, A. M.: Basic laws of turbulent mixing in the surface layer of the atmosphere, Contrib. Geophys. Inst. Acad. Sci. USSR, 151, 163-187, 1954.

Myneni, R., Knyazikhin, Y., and Park, T.: MOD15A2H MODIS/Terra Leaf Area Index/FPAR 8-Day L4 Global $500 \mathrm{~m}$ SIN Grid V006 [Data set], NASA EOSDIS Land Processes DAAC, https://doi.org/10.5067/MODIS/MOD15A2H.006, 2015.

Newman, S. M., Smith, J. A., Glew, M. D., Rogers, S. M., and Taylor, J. P.: Temperature and salinity dependence of sea surface emissivity in the thermal infrared, Q. J. Roy. Meteor. Soc., 131, 2539-2557, https://doi.org/10.1256/qj.04.150, 2005.

Ogawa, K., Schmugge, T., and Jacob, F., Estimation of land surface window $(8-12 \mu \mathrm{m})$ emissivity from multispectral thermal infrared remote sensing: A case study in a part of Sahara Desert, Geophys. Res. Lett., 30, 1067, https://doi.org/10.1029/2003GL016354, 2003.

Oke, T. R.: Boundary layer climates, Routledge, London, New York, p. 435, 1987.

Pavelin, E. G. and Candy, B.: Assimilation of surface-sensitive infrared radiances over land: Estimation of land surface temperature and emissivity, Q. J. Roy. Meteor. Soc., 140, 1198-1208, https://doi.org/10.1002/qj.2218, 2014.

Poulter, B., MacBean, N., Hartley, A., Khlystova, I., Arino, O., Betts, R., Bontemps, S., Boettcher, M., Brockmann, C., Defourny, P., Hagemann, S., Herold, M., Kirches, G., Lamarche, C., Lederer, D., Ottlé, C., Peters, M., and Peylin, P.: Plant functional type classification for earth system models: results from the European Space Agency's Land Cover Climate Change Initiative, Geosci. Model Dev., 8, 2315-2328, https://doi.org/10.5194/gmd8-2315-2015, 2015.

Prince, S. D., Goetz, S. J., Dubayah, R. O., Czajkowski, K. P., and Thawley, M.: Inference of surface and air temperature, atmospheric precipitable water and vapor pressure deficit using advanced very high-resolution radiometer satellite observations: Comparison with field observations, J. Hydrol., 213, 230-29, 1998.

Rabier, F.: Overview of global data assimilation developments in numerical weather-prediction centres, Q. J. Roy. Meteor. Soc., 131, 3215-3233, https://doi.org/10.1256/qj.05.129, 2005.

Rasmussen, M. O., Pinheiro, A. C., Proud, S. R., and Sandholt, I.: Modeling Angular Dependences in Land Surface Temperatures From the SEVIRI Instrument Onboard the Geostationary Meteosat Second Generation Satellites, IEEE T. Geosci. Remote, 48, 3123-3133, 2010.

Ritchie, J. C., Nearing, M. A., Nichols, M. H., and Ritchie, C. A.: Patterns of soil erosion and redeposition on Lucky Hills Watershed, Walnut Gulch Experimental Watershed, Arizona, Catena, 61, 122-130, 2005.

Rowntree, P. R.: Atmospheric parameterization schemes for evaporation over land: Basic concepts and climate modelling aspects, in: Land Surface Evaporation: Measurement and Parameterization, edited by: Schmugge, T. J. and Andre, J. C., 5-29, Springer Verlag, New York, 1991.
Scott, R. L., Jenerette, G. D., Potts, D. L., and Huxman, T. E.: Effects of seasonal drought on net carbon dioxide exchange from a woody-plant-encroached semiarid grassland, J. Geophys. Res.Biogeo, 114, G04004, https://doi.org/10.1029/2008JG000900, 2009.

Scott, R. L., Hamerlynck, E. P., Jenerette, G. D., Moran, M. S., and Barron-Gafford, G. A.: Carbon dioxide exchange in a semidesert grassland through drought-induced vegetation change, J. Geophys. Res., 115, G03026, https://doi.org/10.1029/2010JG001348, 2010.

Scott, R. L., Biederman, J. A., Hamerlynck, E. P., and BarronGafford, G. A.: The carbon balance pivot point of southwestern U.S. semiarid ecosystems: Insights from the 21 st century drought, J. Geophys. Res.-Biogeo., 120, 2612-2624, 2015.

Trigo, I. F., Boussetta, S., Viterbo, P., Balsamo, G., Beljaars, A., and Sandu, I.: Comparison of model land skin temperature with remotely sensed estimates and assessment of surfaceatmosphere coupling, J. Geophys. Res.-Atmos., 120, 1209612111, https://doi.org/10.1002/2015JD023812, 2015.

Twine, T. E., Kustas, W. P., Norman, J. M., Cook, D. R., Houser, P. R., Meyers, T. P., Prueger, J. H., Starks, P. J., and Wesely, M. L.: Correcting eddy-covariance flux underestimates over a grassland, Agr. Forest Meteorol., 103, 279-300, 2000.

Ukkola, A. M., De Kauwe, M. G., Pitman, A. J., Best, M. J., Abramowitz, G., Haverd, V., Decker, M., and Haughton, N.: Land surface models systematically overestimate the intensity, duration and magnitude of seasonal-scale evaporative droughts, Environ. Res. Lett., 11, 104012, https://doi.org/10.1088/17489326/11/10/104012, 2016.

Walters, D. N., Best, M. J., Bushell, A. C., Copsey, D., Edwards, J. M., Falloon, P. D., Harris, C. M., Lock, A. P., Manners, J. C., Morcrette, C. J., Roberts, M. J., Stratton, R. A., Webster, S., Wilkinson, J. M., Willett, M. R., Boutle, I. A., Earnshaw, P. D., Hill, P. G., MacLachlan, C., Martin, G. M., Moufouma-Okia, W., Palmer, M. D., Petch, J. C., Rooney, G. G., Scaife, A. A., and Williams, K. D.: The Met Office Unified Model Global Atmosphere 3.0/3.1 and JULES Global Land 3.0/3.1 configurations, Geosci. Model Dev., 4, 919-941, https://doi.org/10.5194/gmd-4919-2011, 2011.

Walters, D. N., Williams, K. D., Boutle, I. A., Bushell, A. C., Edwards, J. M., Field, P. R., Lock, A. P., Morcrette, C. J., Stratton, R. A., Wilkinson, J. M., Willett, M. R., Bellouin, N., BodasSalcedo, A., Brooks, M. E., Copsey, D., Earnshaw, P. D., Hardiman, S. C., Harris, C. M., Levine, R. C., MacLachlan, C., Manners, J. C., Martin, G. M., Milton, S. F., Palmer, M. D., Roberts, M. J., Rodríguez, J. M., Tennant, W. J., and Vidale, P. L.: The Met Office Unified Model Global Atmosphere 4.0 and JULES Global Land 4.0 configurations, Geosci. Model Dev., 7, 361-386, https://doi.org/10.5194/gmd-7-361-2014, 2014.

Walters, D., Boutle, I., Brooks, M., Melvin, T., Stratton, R., Vosper, S., Wells, H., Williams, K., Wood, N., Allen, T., Bushell, A., Copsey, D., Earnshaw, P., Edwards, J., Gross, M., Hardiman, S., Harris, C., Heming, J., Klingaman, N., Levine, R., Manners, J., Martin, G., Milton, S., Mittermaier, M., Morcrette, C., Riddick, T., Roberts, M., Sanchez, C., Selwood, P., Stirling, A., Smith, C., Suri, D., Tennant, W., Vidale, P. L., Wilkinson, J., Willett, M., Woolnough, S., and Xavier, P.: The Met Office Unified Model Global Atmosphere 6.0/6.1 and JULES Global 
Land 6.0/6.1 configurations, Geosci. Model Dev., 10, 14871520, https://doi.org/10.5194/gmd-10-1487-2017, 2017.

Wan, Z.: MODIS land-surface temperature algorithm theoretical basis document (LST ATBD), Version 3.3, University of California, Santa Barbara, 1999.

Wan, Z.: New refinements and validation of the collection-6 MODIS land-surface temperature/emissivity product, Remote Sens. Environ., 140, 36-45, 2014.

Wan, Z. and Dozier, J.: A generalized split-window algorithm for retrieving land-surface temperature from space, IEEE T. Geosci. Remote, 34, 892-905, 1996.

Wan, Z.: MODIS land-surface temperature algorithm theoretical basis document (LST ATBD), Version 3.3, University of California, Santa Barbara, 1999.

Wan, Z., Zhanga, Y., Zhanga Q., and Lib, Z. L.: Quality assessment and validation of the MODIS global land surface temperature, Int. J. Remote Sens., 25, 261-274, 2004.

Wang, K., Wan, Z., Wang, P., Sparrow, M., Liu, J., and Haginoya, S.: Evaluation and improvement of the MODIS land surface temperature/emissivity products using ground-based measurements at a semi-desert site on the western Tibetan Plateau, Int. J. Remote Sens., 28, 2549-2565, 2007.
Weltz, M. A., Ritchie, J. C., and Fox, H. D.: Comparison of laser and field measurements of vegetation heights and canopy cover, Water Resour. Res., 30, 1311-1319, 1994.

Wilson, K., Goldstein, A., Falge, E., Aubinet, M., Baldocchi, D., Berbigier, P., Bernhofer, C., Ceulemans, R., Dolman, H., Field, C., Grelle, A., Ibrom, A., Law, B. E., Kowalski, A., Meyers, T., Moncrieff, J., Monson, R., Oechel, W., Tenhunen, J., Valentini, R., and Verma, S.: Energy balance closure at FLUXNET sites, Agr. Forest Meteorol., 113, 223-243, 2002.

Zheng, W., Wei, H., Wang, Z., Zeng, X., Meng, J., Ek, M., Mitchell, K., and Derber, J.: Improvement of daytime land surface skin temperature over arid regions in the NCEP GFS model and its impact on satellite data assimilation, J. Geophys. Res., 117, DO6117, https://doi.org/10.1029/2011JD015901, 2012.

Zhu, Y., Derber, J., Collard, A., Dee, D., Treadon, R., Gayno, G., and Jung, J. A.: Enhanced radiance bias correction in the National Centers for Environmental Prediction's Gridpoint Statistical Interpolation data assimilation system, Q. J. Roy. Meteor. Soc., 140, 1479-1492, https://doi.org/10.1002/qj.2233, 2014. 